\title{
The Analytical Objective Hysteresis Model (AnOHM v1.0): methodology to determine bulk storage heat flux coefficients
}

\author{
Ting Sun ${ }^{1,2,3}$, Zhi-Hua Wang ${ }^{4}$, Walter C. Oechel ${ }^{5,6}$, and Sue Grimmond ${ }^{1}$ \\ ${ }^{1}$ Department of Meteorology, University of Reading, Reading, RG6 6BB, UK \\ ${ }^{2}$ Department of Hydraulic Engineering, Tsinghua University, Beijing 100084, China \\ ${ }^{3}$ State Key Laboratory of Hydro-Science and Engineering, Tsinghua University, Beijing 100084, China \\ ${ }^{4}$ School of Sustainable Engineering and the Built Environment, Arizona State University, Tempe, AZ 85287, USA \\ ${ }^{5}$ Global Change Research Group, Department of Biology, San Diego State University, San Diego, CA 92182, USA \\ ${ }^{6}$ Department of Environment, Earth and Ecosystems, The Open University, Milton Keynes, MK7 6AA, UK \\ Correspondence to: Ting Sun (ting.sun@reading.ac.uk) and Sue Grimmond (c.s.grimmond@reading.ac.uk)
}

Received: 8 December 2016 - Discussion started: 10 January 2017

Revised: 18 June 2017 - Accepted: 19 June 2017 - Published: 27 July 2017

\begin{abstract}
The net storage heat flux $\left(\Delta Q_{\mathrm{S}}\right)$ is important in the urban surface energy balance (SEB) but its determination remains a significant challenge. The hysteresis pattern of the diurnal relation between the $\Delta Q_{\mathrm{S}}$ and net all-wave radiation $\left(Q^{*}\right)$ has been captured in the Objective Hysteresis Model (OHM) parameterization of $\Delta Q_{\mathrm{S}}$. Although successfully used in urban areas, the limited availability of coefficients for OHM hampers its application. To facilitate use, and enhance physical interpretations of the OHM coefficients, an analytical solution of the one-dimensional advectiondiffusion equation of coupled heat and liquid water transport in conjunction with the SEB is conducted, allowing development of AnOHM (Analytical Objective Hysteresis Model). A sensitivity test of AnOHM to surface properties and hydrometeorological forcing is presented using a stochastic approach (subset simulation). The sensitivity test suggests that the albedo, Bowen ratio and bulk transfer coefficient, solar radiation and wind speed are most critical. AnOHM, driven by local meteorological conditions at five sites with different land use, is shown to simulate the $\Delta Q_{\mathrm{S}}$ flux well (RMSE values of $\sim 30 \mathrm{~W} \mathrm{~m}^{-2}$ ). The intra-annual dynamics of $\mathrm{OHM}$ coefficients are explored. AnOHM offers significant potential to enhance modelling of the surface energy balance over a wider range of conditions and land covers.
\end{abstract}

\section{Introduction}

The essential role of an integrated land surface model is to physically predict the land-atmosphere interactions by resolving the transfer of energy, water, and trace gases (Katul et al., 2012; Liang et al., 1994; Sellers et al., 1997). Such landatmospheric interactions are strongly modulated by the partitioning of solar energy at the land surface (Chen and Dudhia, 2001; McCumber and Pielke, 1981; Yang and Wang, 2014) which can be considered through the surface energy balance (SEB) equation (Oke, 1988):

$Q^{*}-\Delta Q_{\mathrm{S}}=Q_{H}+Q_{E}$,

where $Q^{*}, \Delta Q_{\mathrm{S}}, Q_{H}$, and $Q_{E}$ are the net all-wave radiation, net storage, turbulent sensible, and latent heat fluxes, respectively. Equation (1) distinguishes the available energy at the land surface (left-hand side) from the heat transfer through turbulent transport (right-hand side).

The turbulent and radiative fluxes $\left(Q^{*}, Q_{H}\right.$, and $\left.Q_{E}\right)$ are more readily measured using standard techniques (e.g. eddycovariance instruments, radiometry) than $\Delta Q_{\mathrm{S}}$ (Offerle et al., 2005; Pauwels and Daly, 2016; Roberts et al., 2006; Wang, 2012). For $\Delta Q_{\mathrm{S}}$ the net energy stored or released by changes in sensible heat within the canopy air layer, roughness elements (e.g. vegetation, buildings in an urban environment), and the ground all have to be considered. The volume of interest extends from the top of the roughness sub-layer to the depth in the ground where the daily averaged vertical net 
heat conduction is zero (see Fig. 2 in Masson et al., 2002); this presents very significant challenges of spatial sampling.

Knowledge of $\Delta Q_{\mathrm{S}}$ is crucial to a wide range of processes and applications: from modelling turbulent heat transfer and boundary layer development to predicting soil thermal fields. In rural sites, or simple bare soil sites, the flux may be a small fraction of the net all-wave radiation (Oliphant et al., 2004). However, in areas where there is more mass, such as cities, the term becomes much more significant (Kotthaus and Grimmond, 2014a) and a key element of the SEB and well-known effects such as the urban heat island.

In urban systems a wide range of techniques have been used to estimate $\Delta Q_{\mathrm{S}}$ (Grimmond et al., 1991; Roberts et al., 2006). These include the following:

a. Heat conduction approach: the weighted average of heat flows through all urban materials and surfaces by solving heat conduction equations - e.g. buildings, streets, vegetated lands (Offerle et al., 2005; Wang et al., 2012; Yang et al., 2014).

b. Thermal mass scheme: the storage heat is inferred from the changes in thermal mass of all components of the urban system (Kerschgens and Kraus, 1990).

c. Heat flux plates: combined measurements from grass and paved surfaces (Kerschgens and Drauschke, 1986; Kerschgens and Hacker, 1985).

d. Parameterization as a function of $Q^{*}$ : either as a linear function (Oke et al., 1981), hyperbolic (cotangent, secant) function (Doll et al., 1985), or hysteresis relation (Camuffo and Bernardi, 1982). The last of these is used in the Objective Hysteresis Model (OHM) (Grimmond et al., 1991).

e. Residual: practical difficulties of direct measurement of $\Delta Q_{\mathrm{S}}$ in urban areas, result in the SEB residual (i.e. $\left.Q^{*}+Q_{F}-\left(Q_{H}+Q_{E}\right)\right)$ frequently being the "preferred" observations (Ao et al., 2016; Ching et al., 1983; Doll et al., 1985; Li et al., 2015; Oke and Cleugh, 1987) (where $Q_{F}$ is the anthropogenic heat flux).

The focus here is on the OHM approach, which is forced by $Q^{*}$ and accounts for the diversity of the surface materials (sub-facets $i$ ) in the measurement source area of interest with weightings $(f)$ for their two- or three-dimensional extent (Grimmond et al., 1991):

$\Delta Q_{\mathrm{S}}=\sum_{i} f_{i}\left(a_{1, i} Q_{i}^{*}+a_{2, i} \frac{\partial Q_{i}^{*}}{\partial t}+a_{3, i}\right)$,

where the $a_{1}, a_{2}$, and $a_{3}$ coefficients are for individual facets determined by least-square regression between $\Delta Q_{\mathrm{S}}$ and $Q^{*}$ using results from observations (e.g. asphalt road (Anandakumar, 1999), wetlands (Souch et al., 1998), forests (Oliphant et al., 2004), or numerical modelling - e.g. urban canyons (Arnfield and Grimmond, 1998) and roofs (Meyn and Oke, 2009). These coefficients capture the net behaviour of a facet type in a typical setting, rather than being required to identify the component materials within a facet (e.g. multiple materials making up a roof, wall, with varying thermal connectivity and individual properties). As such, OHM is one of the less demanding parameterizations, yet does capture a more realistic understanding of the relation between $\Delta Q_{\mathrm{S}}$ by $Q^{*}$ compared with other approaches. Despite the shortage of OHM coefficients for the wide range of facet types found in cities, OHM captures the urban $\Delta Q_{\mathrm{S}}$ overall generally well (Grimmond and Oke, 1999; Järvi et al., 2011, 2014; Karsisto et al., 2015; Roth and Oke, 1995).

OHM is a cornerstone in the urban land surface models SUEWS (Surface Urban Energy And Water Balance Scheme; Järvi et al., 2011, 2014; Ward et al., 2016) and LUMPS (Local-Scale Urban Meteorological Parameterization Scheme; Grimmond and Oke, 2002), and plays an essential role in determining the initial energy partitioning at each time step of the models' simulations. Previous modelling studies (Arnfield and Grimmond, 1998; Meyn and Oke, 2009) have led to better understanding of the OHM coefficients. Solution of the one-dimensional advection-diffusion equation of coupled heat and liquid water transport by Gao et al. $(2003,2008)$ was used to explore the physical relation of OHM coefficients $a_{1}$ and $a_{2}$ to the phase lag between $\Delta Q_{\mathrm{S}}$ and $Q^{*}$. However, insight into $a_{3}$ remain unclear (Sun et al., 2013).

In this paper, the solutions of the one-dimensional advection-diffusion equation of coupled heat and liquid water transport (Gao et al., 2003, 2008) are employed with the SEB (Eq. 1) to investigate more fully the three OHM coefficients, the outcomes of which lead to development of the Analytical Objective Hysteresis Model (AnOHM) (Sect. 2). The Monte Carlo-based subset simulation (Au and Beck, 2001) approach is then used to undertake a sensitivity analysis of AnOHM to surface properties and hydrometeorological conditions (Sect. 3). An offline evaluation of AnOHM's performance for five sites with different land covers (Sect. 4) provides evidence that this is an alternative approach to obtain OHM coefficients. Given that this allows applications across a much wider range of environments and meteorological conditions, we conclude that AnOHM has important implications for land surface modelling (urban and non-urban).

\section{Model development}

\subsection{Parameterization of storage heat flux $\Delta Q_{\mathrm{S}}$ for a land surface}

For a given land surface (e.g. bare soil), the governing heat conduction-advection equation can be written (Gao et al., 
2003, 2010) as

$$
\frac{\partial T}{\partial t}=\lambda \frac{\partial^{2} T}{\mathrm{~d} z^{2}}+W \frac{\partial T}{\partial z}
$$

where $T$ is the temperature at a reference depth $z$ (positive downward), $t$ is time, $\lambda$ is the thermal diffusivity, and $W=$ $\partial \lambda / \partial z-\left(C_{\mathrm{W}} / C_{g}\right) w \varphi$ is the soil water flux density (Ren et al., 2000), with $C_{\mathrm{W}}$ the volumetric heat capacity of water, $C_{g}$ the volumetric heat capacity of soil, $w$ the pore water velocity, and $\varphi$ the volumetric soil water content.

The steady-periodic solution of Eq. (3) corresponding to the principal Earth rotation frequency $(\omega=2 \pi / 24$, in $\operatorname{radh}^{-1}$ ), with boundary condition

$T_{\mathrm{S}}=A_{T_{\mathrm{S}}} \sin (\omega t-\gamma)+\bar{T}_{\mathrm{S}}$

is given by (Gao et al., 2003, 2010)

$T(z, t)=A_{T_{\mathrm{S}}} \exp (-z / M) \sin (\omega t-z / N-\gamma)+\bar{T}_{\mathrm{S}}$,

where $M=\frac{2 \lambda}{\Delta+W}, \quad N=\frac{\Delta}{\omega}$, and $\Delta=\sqrt{\frac{W^{2}+\sqrt{W^{4}+16 \lambda^{2} \omega^{2}}}{2}}$; with $\bar{T}_{\mathrm{S}}, A_{T_{\mathrm{S}}}$, and $\gamma$ denoting the daily mean value, amplitude, and initial phase of surface temperature, respectively, which need to be determined by the boundary conditions imposed by the SEB.

From Fourier's law, the soil heat flux is then given by

$$
\begin{gathered}
G(z, t) \equiv-\frac{k \partial T}{\partial z}=k A_{T_{\mathrm{S}}} \frac{\sqrt{M^{2}+N^{2}}}{M N} \exp \left(-\frac{z}{M}\right) \\
\sin \left(\omega t-\frac{z}{N}-\gamma+\delta\right)
\end{gathered}
$$

where $\delta=\arctan \left(\frac{M}{N}\right)=\arctan \left[\frac{2 \lambda \omega}{(\Delta+W) \Delta}\right]$ and $k$ is the thermal conductivity. In particular, at the surface $z=0$, the ground heat flux $G_{0}$ is given by

$G_{0}(t)=k A_{T_{\mathrm{S}}} \frac{\sqrt{M^{2}+N^{2}}}{M N} \sin (\omega t-\gamma+\delta)$,

and a simple written form of $\Delta Q_{\mathrm{S}}$ (if only one surface) can be given as

$\Delta Q_{\mathrm{S}}=G_{0}=c_{\eta} \sin (\omega t+\eta)$,

where $\eta=\delta-\gamma$ and $c_{\eta}=k A_{T_{\mathrm{S}}} \frac{\sqrt{M^{2}+N^{2}}}{M N}$

Although the above derivation only considers the land surface made of a single material type, the derived $\Delta Q_{\mathrm{S}}$ (Eq. 8) can be adapted for surfaces made of composite materials or volumes given appropriate bulk/ensemble properties.

\subsection{Parameterization of net all-wave radiation $Q^{*}$ for a land surface}

Given the parameterizations of incoming longwave radiation $L_{\downarrow}$, outgoing longwave radiation $L_{\uparrow}$, sensible heat flux $Q_{H}$, latent heat flux $Q_{E}$, and storage heat flux $\Delta Q_{\mathrm{S}}$ as follows:

$$
\begin{aligned}
& L_{\downarrow}=\varepsilon_{\mathrm{a}} \sigma T_{\mathrm{a}}^{4}, \\
& L_{\uparrow}=\underbrace{\varepsilon_{\mathrm{s}} \sigma T_{\mathrm{S}}^{4}}_{1}+\underbrace{\left(1-\varepsilon_{\mathrm{S}}\right) L_{\downarrow}}_{2} \\
& Q_{H}=C_{h} U\left(T_{\mathrm{S}}-T_{\mathrm{a}}\right), \\
& Q_{E}=Q_{H} / \beta, \\
& \Delta Q_{\mathrm{S}}=G_{0} .
\end{aligned}
$$

The boundary condition imposed by the SEB relation can be rewritten as

$$
\begin{aligned}
(1-\alpha) K_{\downarrow} & +\varepsilon_{\mathrm{a}} \sigma T_{\mathrm{a}}^{4}-\varepsilon_{\mathrm{S}} \sigma T_{\mathrm{S}}^{4} \\
& =C_{h} U\left(1+\beta^{-1}\right)\left(T_{\mathrm{S}}-T_{\mathrm{a}}\right)+G_{0},
\end{aligned}
$$

where the turbulent fluxes $Q_{H}$ and $Q_{E}$ are parameterized as functions of temperature gradient $T_{\mathrm{S}}-T_{\mathrm{a}}$ with albedo $\alpha$, bulk transfer coefficient $C_{h}$, wind speed $U$, and Bowen ratio ( $\left.\beta=Q_{H} / Q_{E}\right)$. Theoretically, the second part of Eq. (10) (i.e. $\left.\left(1-\varepsilon_{\mathrm{S}}\right) L_{\downarrow}\right)$ should be accounted for in the estimation of $L_{\uparrow}$ (Oke, 1987); however, given that it is usually less than $\sim 5 \%$ of the first part of the equation (see full discussion in Appendix A) for most land covers (Oke, 1987), here it is omitted from consideration and in the development of AnOHM.

By assuming that the incoming solar radiation $K_{\downarrow}$ and air temperature $T_{\mathrm{a}}$ follow sinusoidal forms through a day as function of the mean value for the day (e.g. $\bar{K}_{\downarrow}$ ) (Sun et al., 2013)

$K_{\downarrow}=A_{K} \sin (\omega t)+\bar{K}_{\downarrow}$,

$T_{\mathrm{a}}=A_{T} \sin (\omega t-\tau)+\bar{T}_{\mathrm{a}}$,

and introducing the solar radiation scale,

$A_{K}^{*}=(1-\alpha) A_{K}$,

and longwave radiation scale (assuming $\varepsilon_{\mathrm{a}} \approx \varepsilon_{\mathrm{s}} \approx \varepsilon$ as a first-order estimate (as AnOHM is insensitive to this parameter; see Sect. 3.2); see clear sky of $\sim 0.85$ (Staley and Jurica, 1972) and urban surfaces of $\sim 0.95$ (Kotthaus et al., 2014):

$$
\begin{aligned}
A_{T}^{*} & =\left(4 \varepsilon \sigma \bar{T}_{\mathrm{a}}^{3}+\left(1+\beta^{-1}\right) C_{h} U\right) A_{T} \\
& =\left(f_{L}+f_{T}\right) A_{T}=f A_{T},
\end{aligned}
$$

where $\tau$ denotes phase differences between $T_{\mathrm{a}}$ and $K_{\downarrow}$, the $f=f_{L}+f_{T}$ consists of the longwave energy redistribution factor: $f_{L}=4 \varepsilon \sigma \bar{T}_{\mathrm{a}}^{3}$ and a turbulent energy redistribution factor: $f_{T}=\left(1+\beta^{-1}\right) C_{h} U$. Linearizing the fourth-order longwave expressions of temperature at mean daily air temperature $\overline{T_{\mathrm{a}}}$ (Sun et al., 2013), the values of $\overline{T_{\mathrm{S}}}$ and $A_{T_{\mathrm{S}}}$ are ob- 
tained:

$$
\begin{aligned}
& \bar{T}_{\mathrm{S}}=\frac{1-\alpha}{f} \bar{K}_{\downarrow}+\bar{T}_{\mathrm{a}} \\
& A_{T_{\mathrm{S}}}=\frac{f M N \sin (\tau)}{N(f M+k) \sin (\gamma)-k M \cos (\gamma)} A_{T} \\
& =\frac{1}{\sqrt{M_{*}^{2}+N_{*}^{2}}} \frac{\sin (\tau)}{\sin (\gamma-\zeta)} A_{T} \\
& =\chi_{\gamma} A_{T},
\end{aligned}
$$

where $\zeta=\arctan \left(N_{*} / M_{*}\right), \gamma=\zeta+\arctan \left(\frac{\sin (\tau)}{\cos (\tau)+A_{K}^{*} / A_{T}^{*}}\right)$, $M_{*}=1+k /(f M), \quad N_{*}=k /(f N) \quad$ and $\quad \chi_{\gamma}=$ $\frac{1}{\sqrt{M_{*}^{2}+N_{*}^{2}}} \frac{\sin (\tau)}{\sin (\gamma-\zeta)}$.

The net all-wave radiation $Q^{*}$ is parameterized as

$$
\begin{aligned}
Q^{*} & =(1-\alpha) K_{\downarrow}+\varepsilon \sigma T_{\mathrm{a}}^{4}-\varepsilon \sigma T_{\mathrm{S}}^{4} \\
& =(1-\alpha)\left(A_{K} \sin (\omega t)+\bar{K}_{\downarrow}\right)+f_{L}\left(T_{\mathrm{a}}-T_{\mathrm{S}}\right) \\
& =c_{\varphi} \sin (\omega t+\varphi)+\frac{f_{L}}{f}(1-\alpha) \bar{K}_{\downarrow}
\end{aligned}
$$

where $\varphi=\arctan \left[\frac{\left(\chi_{\gamma} \sin (\gamma)-\sin (\tau)\right)}{\left(f A_{K}^{*}\right) /\left(f_{L} A_{T}^{*}\right)-\left(\chi_{\gamma} \cos (\gamma)-\cos (\tau)\right)}\right]$ and

$c_{\varphi}=\sqrt{\left[\frac{\left(f A_{K}^{*}\right)^{2}}{\left(f_{L} A_{T}^{*}\right)^{2}}-\left(\chi_{\gamma} \cos (\gamma)-\cos (\tau)\right)\right]^{2}+\left[\beta_{\gamma} \sin (\gamma)-\sin (\tau)\right]^{2}}$.

\subsection{Derivation of AnOHM coefficients}

Based on the above parameterizations of $Q^{*}$ (Eq. 21) and $\Delta Q_{\mathrm{S}}$ (Eq. 8), together with OHM for a specific surface:

$\Delta Q_{\mathrm{S}}=a_{1} Q^{*}+a_{2} \frac{\partial Q^{*}}{\partial t}+a_{3}$,

the coefficients can be readily derived from the parameterization in Sect. 2.2, as

$$
\begin{aligned}
a_{1} & =\frac{c_{\eta}}{c_{\varphi}} \cos (\eta-\varphi), \\
a_{2} & =\frac{c_{\eta}}{\omega c_{\varphi}} \sin (\eta-\varphi), \\
a_{3} & =-\frac{c_{\eta}}{c_{\varphi}} \cos (\eta-\varphi) \cdot \frac{f_{T}}{f}(1-\alpha) \bar{K}_{\downarrow} \\
& =-a_{1} \cdot \frac{f_{T}}{f}(1-\alpha) \bar{K}_{\downarrow} .
\end{aligned}
$$

In the densest parts of cities, the anthropogenic heat $\left(Q_{F}\right)$ often has a large influence on the SEB and it needs to be accounted for (Allen et al., 2011; Chow et al., 2014; Nie et al., 2014; Sailor, 2011). This requires the governing SEB relation (Eq. 14) to be rewritten:

$$
\begin{aligned}
(1-\alpha) K_{\downarrow} & +\varepsilon \sigma T_{\mathrm{a}}^{4}-\varepsilon \sigma T_{\mathrm{S}}^{4}+Q_{F} \\
& =C_{h} U\left(1+\beta^{-1}\right)\left(T_{\mathrm{S}}-T_{\mathrm{a}}\right)+G_{0} .
\end{aligned}
$$

Assuming $Q_{F}$ is diurnally invariant (as a first-order estimate - e.g. Best and Grimmond, 2016), the derivation
(Sect. 2.2) can be extended to include a first-order estimate of $Q_{F}$ to obtain

$$
\begin{aligned}
a_{3 F} & =-\frac{c_{\eta}}{c_{\varphi}} \cos (\eta-\varphi) \cdot \frac{f_{T}}{f}(1-\alpha) \bar{K}_{\downarrow}-Q_{F} \\
& =-a_{1} \cdot \frac{f_{T}}{f}(1-\alpha) \bar{K}_{\downarrow}-Q_{F},
\end{aligned}
$$

where $a_{3 F}$ (subscript " $F$ " indicates the inclusion of $Q_{F}$ ). The other two coefficients remain unchanged.

\subsection{Physical interpretations of AnOHM coefficients}

Based on the parameterizations of AnOHM coefficients (Eqs. 23, 24, 25/27), physical interpretations can be more fully described compared with OHM:

a. $a_{1}$ characterizes the ratio of $\Delta Q_{\mathrm{S}}$ and $Q^{*}$ and depends on the energy scales (i.e. $c_{\eta}$ and $c_{\varphi}$ ) and their phase difference (i.e. $\eta-\varphi$ ). The energy scales, representing daily amplitudes of $\Delta Q_{\mathrm{S}}$ and $Q^{*}$, determine the overall magnitude, while the phase difference moderates the ratio value.

b. $a_{2}$ accounts for the temporal changes in $\Delta Q_{\mathrm{S}}$ and $Q^{*}$ by including the principal Earth rotation frequency $\omega$, in addition to the same determinants of $a_{1}$ (i.e. $c_{\eta}, c_{\varphi}$, and $\eta-\varphi)$. The complementary sinusoidal functions, with phase difference (i.e. $\sin (\eta-\varphi)$ and $\cos (\eta-\varphi)$ ), in the formulations of $a_{1}$ and $a_{2}$ are inversely related with a stronger lag effect from $a_{2}$, and less contribution to $\Delta Q_{\mathrm{S}}$ by $Q^{*}$ (i.e. smaller $a_{1}$ ).

c. $a_{3}$ (or $a_{3 F}$ ) indicates the baseline $\Delta Q_{\mathrm{S}}$ determined by energy redistribution factors (i.e. $f_{T}$ and $f$ ) and energy inputs (i.e. $\bar{K}_{\downarrow}$, and $Q_{F}$ if anthropogenic heat is considered) as well as $a_{1}$. It can be inferred from Eq. (2) that the nocturnal $\Delta Q_{\mathrm{S}}$ is largely determined by $a_{3}$ when the absolute values and variability of $Q^{*}$ are small at night. A larger daytime energy input (i.e. $\bar{K}_{\downarrow}$, and $Q_{F}$ if anthropogenic heat is considered) suggests more heat released at night.

\section{Sensitivity analysis}

Given the complex dependence of AnOHM coefficients on surface properties and meteorological forcing (Sect. 2.3), the impacts of these coefficients are assessed further by a sensitivity analysis.

\subsection{Subset simulation}

To improve the computational efficiency of undertaking Monte Carlo sensitivity analyses, subset simulation is used (Au and Beck, 2001). This is an adaptive stochastic simulation procedure with particular efficiency in analysing the 
short-tail of a distribution probability (while also adaptable to long-tail scenarios) (Wang et al., 2011).

If the probability that a critical response $Y$ exceeds a threshold $y, P(Y>y)$, a range of exceedance regions can be specified and sampled using Markov chains. Initially a direct Monte Carlo method is used to choose possible values for the parameter of interest in the anticipated range with a specified distribution (or probability distribution function, PDF) of the uncertainty. From this (level 0), the first exceedance level probability is determined, $F_{1}$ at which $P\left(Y>y_{1}\right)$. Then a Markov chain Monte Carlo (MCMC) procedure is used to generate samples of a given conditional probability $p_{0}$, leading to the exceedance of $y_{1}$ in the earlier simulations. This procedure is repeated, for exceedance events $F_{i}$ at which $P\left(Y>y_{i}\right)=p_{0}^{i}, i=1,2,3, \ldots$, until simulations reach a target exceedance probability, e.g. associated with rare events or risk analysis. Further details of this subset simulation process are provided in Wang et al. (2011).

Subset simulation efficiently generates conditional samples with Metropolis algorithms (Hastings, 1970; Metropolis et al., 1953). This is the basis of MCMC. To generate samples that successively approach a certain conditional probability, a specific Markov chain is designed with the target PDF as its limiting stationary distribution trend as its length increases. The selection of a distribution is key as this controls the next sample generated from the current one. Ideally, the distribution selection would be automatic but this has an efficiency cost relative to the robustness benefit. For the surface parameters (Table 1a) and hydrometeorological forcing (Table 1b) analyses a normal distribution PDF is used (Au and Beck, 2003; Au et al., 2007), with three conditional levels $\left(N_{\text {level }}=3\right)$ and a conditional probability of $p_{0}=0.1-$ i.e. at each level the highest $10 \%$ of the outputs are considered to exceed the intermediate threshold. As such, the threelevel simulation can effectively capture a rare event with the target exceedance probability of $10^{-4}$ (i.e. the probability of occurrence is less than 1 in 10000) and generate appropriate samples of different conditional probabilities.

The metric $S$ (in \%), used to indicate the sensitivity of the model output $Y$ to a specific uncertainty parameter $X$ (Wang et al., 2011), is

$S=\left[\frac{1}{N_{\text {level }}} \sum_{i=1}^{N_{\text {level }}} \frac{E\left[X \mid Y>y_{i}\right]-E[X]}{E[X]}\right] \times 100$

where $i=1,2, \ldots, N_{\text {level }}$ is the index of conditional sampling level, $E[X]$ is the expectation that the unconditional distribution of a specific uncertainty parameter $X$, while $E\left[X \mid Y>y_{i}\right]$ is the expectation of $X$ at conditional level $i$. A positive (negative) $S$ indicates an increase will lead to increase (decrease) in simulated value. Hence the sign of $S$ indicates the impact of a change in parameter uncertainty. The absolute magnitude of $S$ indicates the sensitivity.
This assessment does not consider if the simulated values have low probability. Later analyses (Sect. 4) consider the simulation results relative to observed fluxes.

\subsection{Impacts of surface properties}

Following the sensitivity analysis of AnOHM coefficients to the surface properties, the distributions of conditional samples for thermal conductivity $k$, bulk heat capacity $C_{p}$, and emissivity $\varepsilon$ are similar to the original proposal distributions (Fig. 1), implying weak dependence of $a_{1}, a_{2}$, and $a_{3}$ on these properties. However, for albedo $(\alpha)$ both $a_{2}$ and $a_{3}$ are sensitive, but $a_{1}$ is not; changes in inverse Bowen ratio $\left(\beta^{-1}\right)$ impact all three coefficients; and the bulk transfer coefficient $C_{h}$ impacts $a_{1}$ and $a_{2}$, but has little effect on $a_{3}$.

Using $S$ (Eq. 28) to quantify this, it is found that the surface properties $\left(k, C_{p}\right.$, and $\varepsilon$ ) have less sensitivity, with less skewed conditional samples between levels, so $S$ values close to 0 (Fig. 2). The $S$ of $k$ is the largest of the three. From the $S$ results for the $\alpha$ sensitivity analysis (Fig. 2), it is apparent that an increase in $\alpha$ will increase $a_{1}$ while decreasing $a_{2}$ and $a_{3}$, whereas the reverse occurs for $\beta^{-1}$ and $C_{h}$ (i.e. their decreases leads to larger $a_{2}$ and $a_{3}$ values but smaller $a_{1}$ ).

From this, the links between the key surface parameters and the storage heat flux can be considered. With an increase in $\alpha$, there is reduced solar energy in the SEB. This reduces the temporal change in $\Delta Q_{\mathrm{S}}$ (smaller $a_{2}$ ) and decreases the baseline value of $\Delta Q_{\mathrm{S}}$ ( smaller $\left.a_{3}\right)$; larger $\beta^{-1}$ indicates that more available energy is dissipated by $Q_{E}$ than by $Q_{H}$, leading to decreased $T_{\mathrm{S}}$ and $\Delta Q_{\mathrm{S}}$ (smaller $a_{1}$ ); a smaller portion of $Q^{*}$ will be dissipated by $\Delta Q_{\mathrm{S}}$ (smaller $a_{1}$ ) as the increased $C_{h}$ can facilitate the turbulent convection and thus increase the total turbulent fluxes.

\subsection{Impacts of hydrometeorological conditions}

Similarly, the sensitivity of AnOHM to hydrometeorological variables is explored (Fig. 3). The air temperature (range, mean) and water flux density related variables (i.e. $A_{T}, \bar{T}_{\mathrm{a}}$, and $W$ ) have minimal influence on the skewness of the conditional samples. In contrast, the incoming shortwave (solar) radiation (range, mean) and wind-related variables (i.e. $A_{K}$, $\bar{K}_{\downarrow}$, and $U$ ) and the phase lag $\tau$ between $K_{\downarrow}$ and $T_{\mathrm{a}}$ have large impacts. In terms of the greatest impact on the coefficients $\left(a_{1}, a_{2}\right.$, and $\left.a_{3}\right): A_{K}$ and $U$ influences $a_{1}, \tau$ impacts $a_{2}$, and $a_{3}$ responds more to $A_{K}$ and $\bar{K}_{\downarrow}$ than the other variables.

Variables that strongly modulate the interactions between $\Delta Q_{\mathrm{S}}$ and $Q^{*}$ can be informed by the $S$ results (Fig. 4). For instance, a greater range in $K_{\downarrow}$ (i.e. larger $A_{K}$ ) will occur with larger energy input from solar radiation, leading to stronger heating of the near-surface atmosphere and a smaller portion to $\Delta Q_{\mathrm{S}}$ (smaller $a_{1}$ ) but higher baseline $\Delta Q_{\mathrm{S}}$ (larger $\left.a_{3}\right)$. This is consistent with a reduction in $\bar{K}_{\downarrow}$ having a decrease in $a_{3}$. The temporal change in $\Delta Q_{\mathrm{S}}$ is highly correlated with the change in $\tau$, an increase in which implies a 
Table 1. Range of values used as basis for the sensitivity analysis: (a) surface parameters and (b) hydrometeorological variables. All are assumed to have normal PDF. Values of surface parameters are based on values reported in Stull (1988).

\begin{tabular}{|c|c|c|c|c|c|c|}
\hline Parameter/variable & & Unit & Min & Max & Mean & Standard deviation \\
\hline \multicolumn{7}{|l|}{ (a) Surface } \\
\hline Thermal conductivity & $k$ & $\mathrm{~W} \mathrm{~m}{ }^{-1} \mathrm{~K}^{-1}$ & 0 & 3 & 1.2 & 0.1 \\
\hline Bulk material heat capacity & $C_{p}$ & $\mathrm{MJ} \mathrm{m}^{-3} \mathrm{~K}^{-1}$ & 0 & 4 & 2.0 & 0.04 \\
\hline Albedo & $\alpha$ & - & 0 & 1 & 0.27 & 0.07 \\
\hline Emissivity & $\varepsilon$ & - & 0.8 & 1.0 & 0.93 & 0.025 \\
\hline Midday* mean Bowen ratio (inverse) & $\beta^{-1}$ & - & 0 & 20 & 0.05 & 0.05 \\
\hline Bulk transfer coefficient & $C_{h}$ & $\mathrm{~J} \mathrm{~m}^{-3} \mathrm{~K}^{-1}$ & 0 & 8 & 4 & 0.5 \\
\hline \multicolumn{7}{|l|}{ (b) Hydrometeorological } \\
\hline Amplitude or range of the daily incoming shortwave radiation & $A_{K}$ & $\mathrm{~W} \mathrm{~m}^{-2}$ & 0 & 1200 & 800 & 200 \\
\hline Mean daytime incoming shortwave radiation & $\bar{K}_{\downarrow}$ & $\mathrm{W} \mathrm{m}^{-2}$ & 0 & 500 & 200 & 50 \\
\hline Amplitude or range of the daily air temperature & $A_{T}$ & ${ }^{\circ} \mathrm{C}$ & 0 & 15 & 8 & 2 \\
\hline Mean daily air temperature & $\bar{T}_{\mathrm{a}}$ & ${ }^{\circ} \mathrm{C}$ & 0 & 40 & 30 & 7.5 \\
\hline Phase lag between radiation and air temperature & $\tau$ & $\mathrm{rad}$ & 0 & $\pi / 2$ & $\pi / 4$ & $\pi / 10$ \\
\hline Mean daytime wind speed & $U$ & $\mathrm{~m} \mathrm{~s}^{-1}$ & 0 & 4 & 2 & 0.5 \\
\hline Mean daily water flux density & $W$ & $10^{-7} \mathrm{~m}^{3} \mathrm{~s}^{-1} \mathrm{~m}^{-2}$ & 0 & 100 & 10 & 5 \\
\hline
\end{tabular}

* midday period: 1000-1400 local standard time.

Table 2. Characteristics of the flux towers at the study sites.

\begin{tabular}{|c|c|c|c|c|c|}
\hline Site & UK-Ldn & US-Wlr & CA-NS5 & US-SRM & US-SO4 \\
\hline Location & $51.50^{\circ} \mathrm{N}, 0.12^{\circ} \mathrm{W}$ & $37.52^{\circ} \mathrm{N}, 96.86^{\circ} \mathrm{W}$ & $55.86^{\circ} \mathrm{N}, 98.49^{\circ} \mathrm{W}$ & $31.82^{\circ} \mathrm{N}, 110.87^{\circ} \mathrm{W}$ & $33.38^{\circ} \mathrm{N}, 116.64^{\circ} \mathrm{W}$ \\
\hline Land cover classification & Urban/built-up & Grassland & $\begin{array}{l}\text { Evergreen needleleaf } \\
\text { forest }\end{array}$ & Woody savannas & Closed shrublands \\
\hline Land cover code & URB & GRA & ENF & WSA & $\mathrm{CSH}$ \\
\hline Study year & 2011 & 2003 & 2004 & 2004 & 2005 \\
\hline Reference & $\begin{array}{l}\text { Kotthaus and Grim- } \\
\text { mond }(2014 a, b)\end{array}$ & $\begin{array}{l}\text { Klazura et al. (2006), } \\
\text { Coulter et al. (2006) }\end{array}$ & Goulden et al. (2006) & Scott et al. (2009) & Luo et al. (2007) \\
\hline
\end{tabular}

slower response of the surface to solar radiation and an overall decrease in $\Delta Q_{\mathrm{S}}$ (smaller $a_{1}, a_{2}$, and $a_{3}$ ). The greater sensitivity to $\tau$ of $a_{2}$ is a key part of the original hysteresis nature of the heating/cooling of a surface. The sensitivity responses of $a_{1}, a_{2}$, and $a_{3}$ to $U$ are very consistent with those to $C_{h}$, suggesting the similar pathway that turbulent fluxes (i.e. $Q_{H}$ and $Q_{E}$ ) modulate $\Delta Q_{\text {s. }}$. As $W$ mostly influences the heat conduction-diffusion in the underlying surface as thermal properties (i.e. $C_{p}$ and $k$ ), less dependence is observed on it. This is similar with $C_{p}$ and $k$.

\section{Model evaluation}

In this section, the actual ability of AnOHM to determine the storage heat flux relative to observations is evaluated using $30 \mathrm{~min}$ observations from five sites of different land use/covers (Table 2). The measurements include turbulent sensible and latent fluxes, along with incoming and outgoing shortwave and longwave radiation and basic meteorological variables (see Kotthaus and Grimmond, 2014a, b; Klazura et al., 2006; Coulter et al., 2006; Goulden et al., 2006; Scott et al., 2009; Luo et al., 2007, for details). Anthropogenic heat flux $Q_{F}$ at the urban site (i.e. UK-Ldn) is estimated using the GreaterQF model (Iamarino et al., 2011); the heat storage flux $\Delta Q_{\mathrm{S}}$ is thus estimated as the modified residual of urban energy balance as $\Delta Q_{\mathrm{S}}=Q^{*}+0.75 Q_{F}-1.2\left(Q_{H}+Q_{E}\right)$ (Kotthaus and Grimmond, 2014a, b), which is then used in this evaluation. A similar approach for estimating $\Delta Q \mathrm{~s}$ (i.e. residual of surface energy balance, $\Delta Q_{\mathrm{S}}=Q^{*}+Q_{F}-$ $\left.\left(Q_{H}+Q_{E}\right)\right)$ is applied at the other (non-urban) sites but with $Q_{F}=0$.

AnOHM is first calibrated with observations under sunny conditions, when the assumptions of AnOHM are best satisfied (i.e. diurnal cycles of $K_{\downarrow}$ and $T_{\mathrm{a}}$ follow sinusoidal forms), to obtain surface properties required by AnOHM (Table 3 ). As the Bowen ratio $\beta$ varies daily and monthly (Kotthaus and Grimmond, 2014a, b), $\beta$ is either determined as the daily value if available, or based on the observation-based monthly climatology (Table 3 ). The seasonality in albedo $\alpha$ is accounted for also by using its monthly climatology (Table 3). AnOHM is driven by atmospheric forcing (i.e. $K_{\downarrow}$, $T_{\mathrm{a}}$, and $\left.U\right)$ and/or their derived scales $\left(A_{K}, \bar{K}_{\downarrow}, A_{T}, \bar{T}_{\mathrm{a}}\right.$, and $\tau$ ) to generate the OHM coefficients (i.e. $a_{1}, a_{2}$, and $a_{3}$, see 

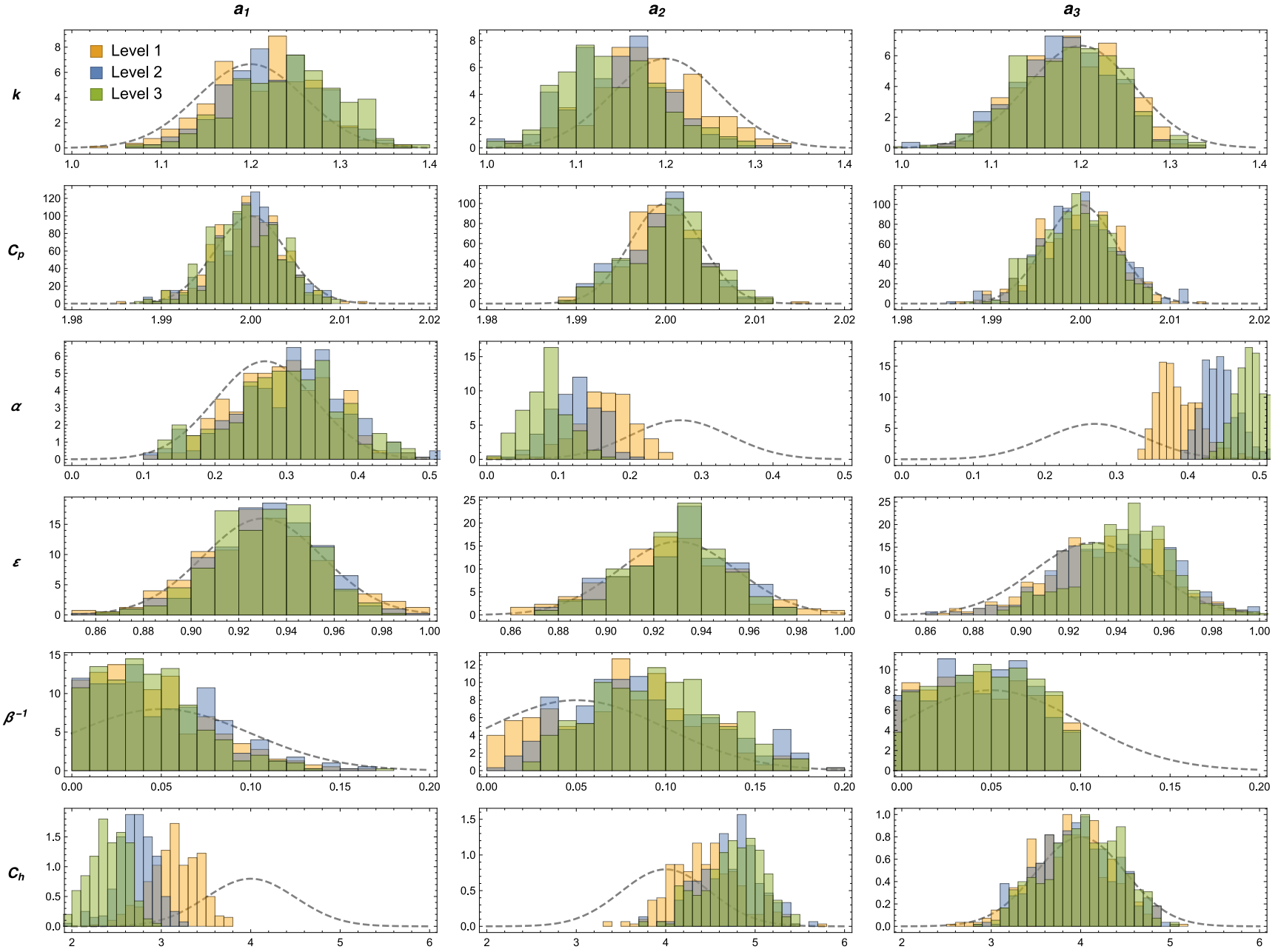

Figure 1. Histograms of conditional samples at different conditional levels for surface property parameters (rows from top: thermal conductivity $k$ in $\mathrm{W} \mathrm{m}^{-1} \mathrm{~K}^{-1}$, heat capacity $C_{p}$ in $\mathrm{MJ} \mathrm{m}^{-3} \mathrm{~K}^{-1}$, albedo $\alpha$, emissivity $\varepsilon$, inverse Bowen ratio $\beta^{-1}$, and bulk transfer coefficient $C_{h}$ in $\mathrm{J} \mathrm{m}^{-3} \mathrm{~K}^{-1}$ ) with AnOHM coefficients as the model output (columns from left: $a_{1}, a_{2}$ and $a_{3}$ ). Each subplot $x$ axis is the parameter value and $y$ axis is the PDF value. The original proposal distribution (dashed line) and simulation levels (different colours) are shown.

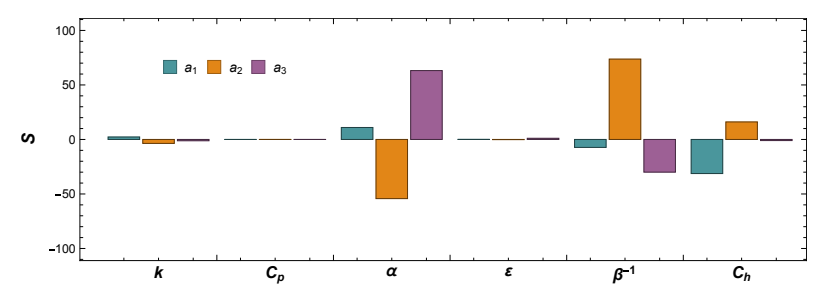

Figure 2. Relative variation in sensitivity ( $S, \%$, Eq. 28$)$ to surface parameters. See Fig. 1 for further details.

Fig. 5), from which the net heat storage flux $\Delta Q_{\mathrm{S}}$ can be predicted (Fig. 6) using the observed $Q^{*}$ with Eq. (2).

To examine the seasonality of the OHM coefficients, rather than the daily variations in hydrometeorological forcing, LOESS (LOcally wEighted Scatter-plot Smoother; Cleveland and Devlin, 1988) curves are obtained to filter out day- to-day variations in the OHM coefficients (see Appendix $\mathrm{B}$ for a direct comparison of these coefficients by different modelling and observational regression approaches). Intraannual variations are found in all the three OHM coefficients (Fig. 5), indicating the strong impact of seasonality of meteorological conditions. These controls, as indicated by Eqs. (23)-(25/27), are complex and will vary with local conditions. For instance, comparison of OHM coefficients between the AnOHM predictions (LOESS fitted solid lines in Fig. 5) and observations at an asphalt road site in Alland, Austria, reported in Anandakumar (1999) (empty squares in Fig. 5) demonstrates differences in $a_{1}$ (Fig. 5a) and $a_{2}$ (Fig. 5b) but general similarity in $a_{3}$ (Fig. 5c). Compared to $a_{1}$ and $a_{2}$, it is noteworthy that, in addition to the $S$ results (see Fig. 4) given the more explicit mechanism by which the atmospheric conditions moderate $a_{3}$ (see Eqs. 25 and 27), such seasonality in $a_{3}$ is predicted by AnOHM, and evident 
$a_{1}$
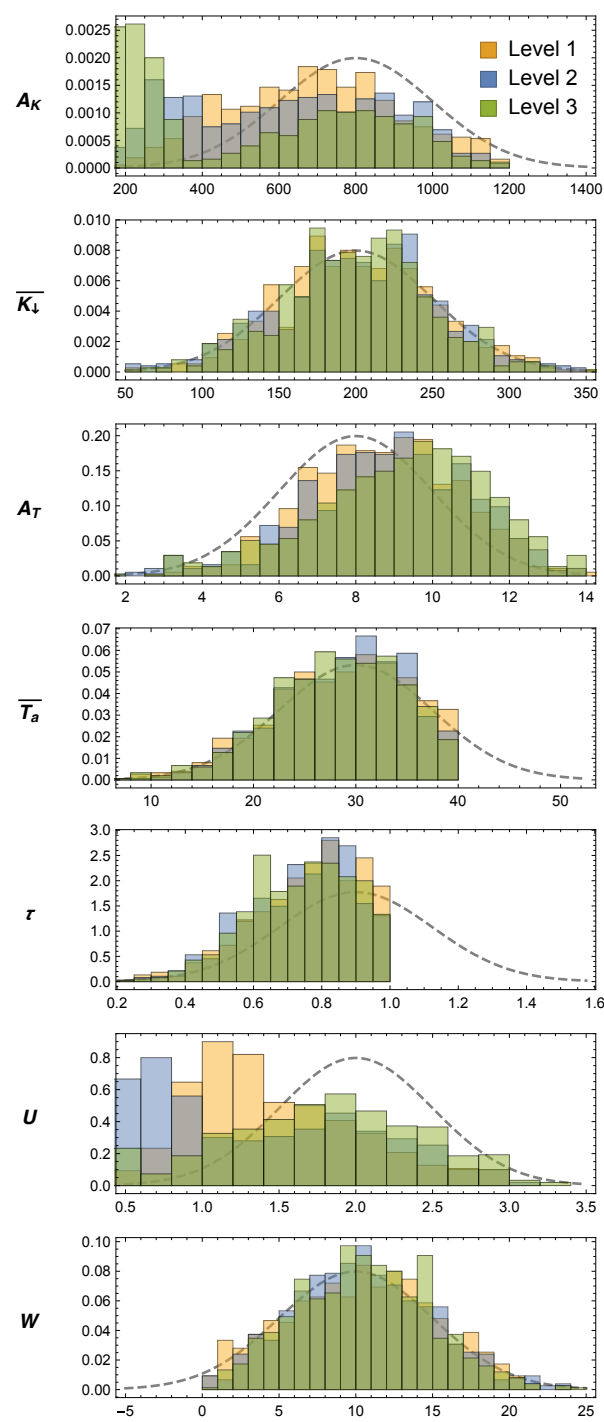

$a_{2}$
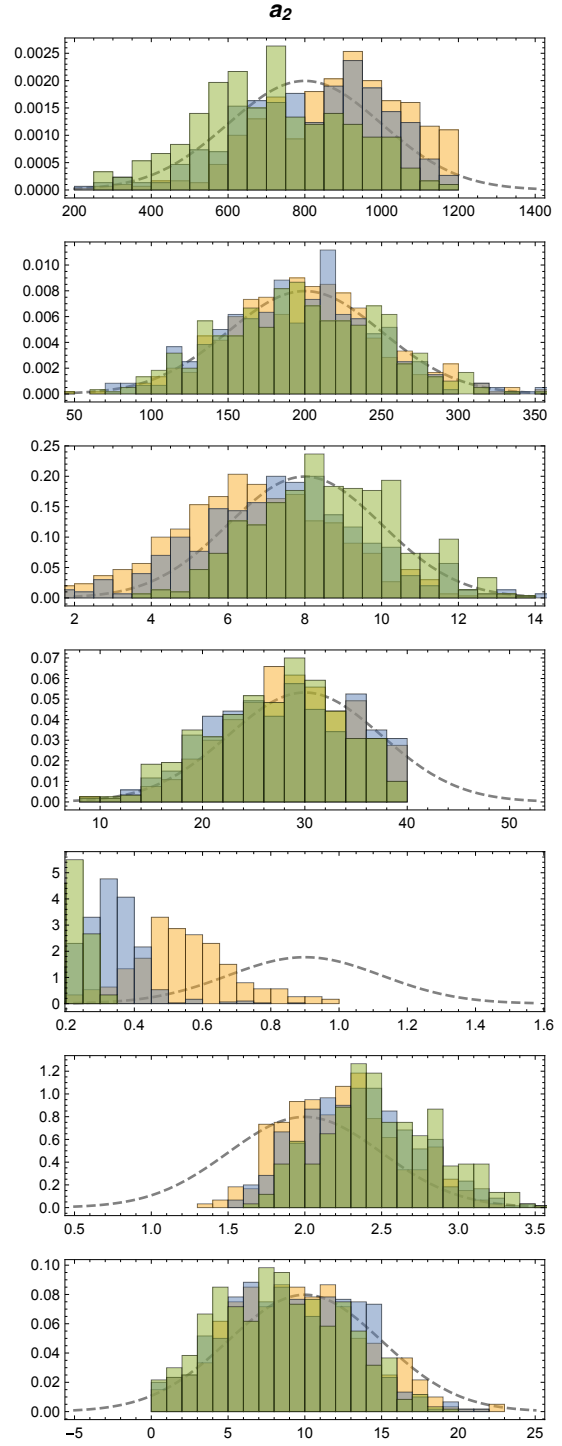

$a_{3}$
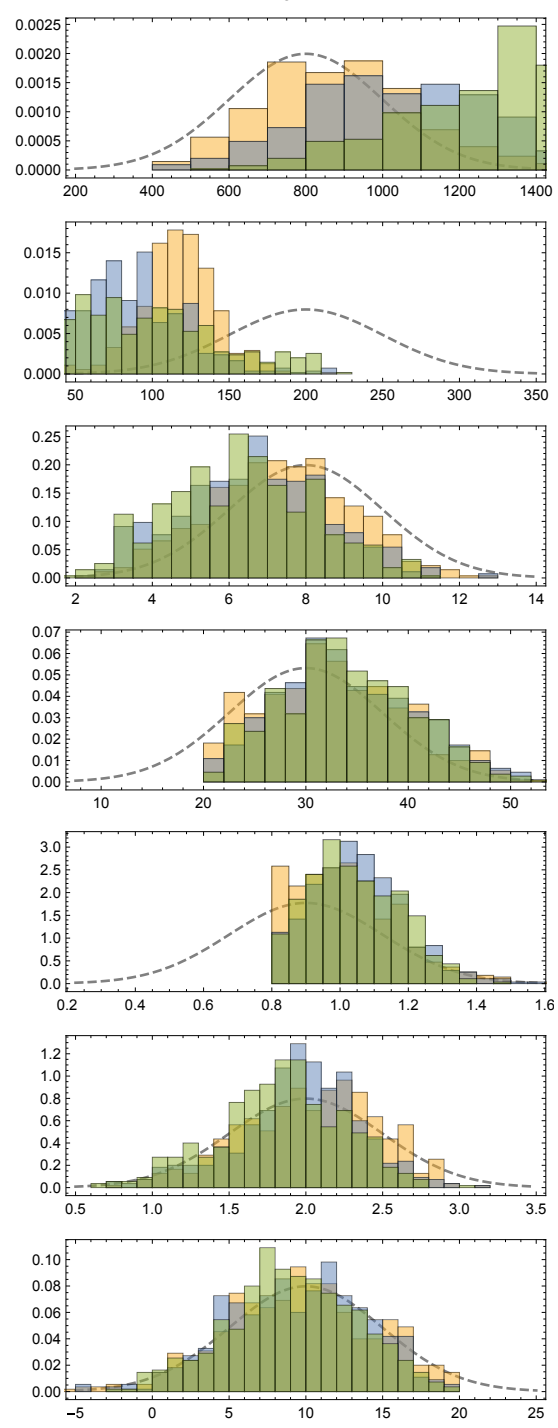

Figure 3. Histograms of conditional samples at different conditional levels for ambient forcing parameters (rows from top: incoming solar radiation amplitude $A_{K}$ in $\mathrm{W} \mathrm{m}^{-2}$ and its daytime mean $\bar{K}_{\downarrow}$ in $\mathrm{W} \mathrm{m}^{-2}$, air temperature amplitude $A_{T}$ in ${ }^{\circ} \mathrm{C}$ and its daily mean $\bar{T}_{\mathrm{a}}$ in ${ }^{\circ} \mathrm{C}$, the phase lag $\tau$ in rad between $K_{\downarrow}$ and $T_{\mathrm{a}}$, wind speed $U$ in $\mathrm{m} \mathrm{s}^{-1}$, and water flux density $W$ in m s${ }^{-1}$ ) with AnOHM coefficients as the model output (columns from left: $a_{1}, a_{2}$ and $a_{3}$ ). As Fig. 1.

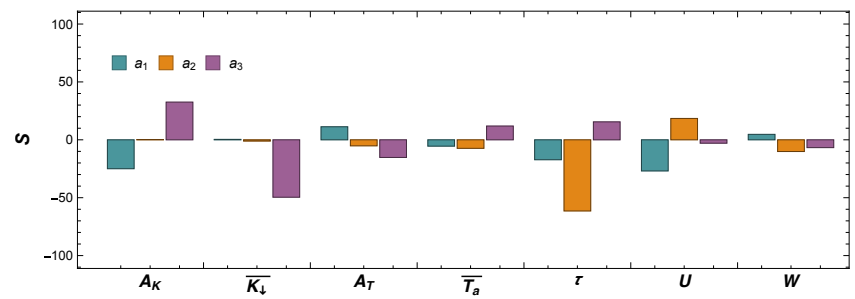

Figure 4. Relative variation in sensitivity ( $S, \%$, Eq. 28$)$ to forcing parameters. See Fig. 3 for further details. in the observations (Fig. 5c, also Ward et al., 2013). Larger $\bar{K}_{\downarrow}$ in warm seasons (May-September) will lead to smaller $a_{3}$ (Eqs. 25, 27) and vice versa.

The AnOHM simulated and observed $\Delta Q_{\mathrm{S}}$ agree well at the five different land cover sites, with RMSE values of $\sim 30 \mathrm{~W} \mathrm{~m}^{-2}$. For comparison purposes, it is noted that the urban land surface model comparison (Best and Grimmond, 2015; Grimmond et al., 2011) found $\Delta Q_{\mathrm{S}}$ to be the most poorly represented among all the SEB components with the best RMSE values of $53 \mathrm{~W} \mathrm{~m}^{-2}$ (Lipson et al., 2017). Although the much smaller $\Delta Q_{\mathrm{S}}$ RMSE obtained by AnOHM uses a prescribed Bowen ratio in the offline evaluation, such improvement indicates the ability of AnOHM to simulate 
Table 3. Surface properties used in AnOHM simulation for the study sites based on calibration. The values of $\alpha$ and $\beta$ are monthly climatology from January to December and are used when observations are not available (see Table 1 for notation definition).

\begin{tabular}{lllllll}
\hline \multirow{2}{*}{ Parameter } & \multirow{2}{*}{ Unit } & \multicolumn{5}{c}{ Site } \\
\cline { 3 - 7 } & & UK-Ldn & US-Wlr & CA-NS5 & US-SRM & US-SO4 \\
\hline$k$ & $\mathrm{~W} \mathrm{~m}^{-1} \mathrm{~K}^{-1}$ & 2.8 & 0.43 & 0.51 & 0.41 & 0.56 \\
$C_{p}$ & $\mathrm{MJ} \mathrm{m}^{-3} \mathrm{~K}^{-1}$ & 2.4 & 0.31 & 0.36 & 0.56 & 0.27 \\
$\alpha$ & - & $0.24,0.24$, & $0.29,0.29$, & $0.30,0.29$, & $0.13,0.17$, & $0.22,0.11$, \\
& & $0.22,0.20$, & $0.17,0.18$, & $0.22,0.15$, & $0.16,0.14$, & $0.11,0.10$, \\
& $0.14,0.13$, & $0.18,0.12$, & $0.10,0.10$, & $0.13,0.12$, & $0.11,0.10$, \\
& & $0.12,0.14$, & $0.11,0.10$, & $0.10,0.11$, & $0.13,0.15$, & $0.10,0.10$, \\
& & $0.18,0.24$, & $0.19,0.13$, & $0.22,0.24$, & $0.14,0.19$, & $0.11,0.10$, \\
$\varepsilon$ & & $0.24,0.18$ & $0.24,0.35$ & $0.28,0.30$ & $0.13,0.18$ & $0.17,0.24$ \\
$\beta$ & - & 0.92 & 0.93 & 0.95 & 0.95 & 0.92 \\
& - & $6.1,5.1$, & $2.9,0.8$, & $6.1,6.0$, & $1.9,5.5$, & $1.5,1.4$, \\
& & $8.3,7.9$, & $7.6,2.7$, & $8.7,8.0$, & $3.3,2.0$, & $1.9,3.0$, \\
& & $5.4,3.9$, & $0.3,0.3$, & $1.9,1.6$, & $10.1,9.7$, & $1.4,1.4$, \\
& & $5.3,4.2$, & $0.3,0.8$, & $0.7,0.7$, & $2.0,0.9$, & $2.1,1.2$, \\
& & $5.2,4.3$, & $0.5,0.7$, & $1.3,1.4$, & $3.0,4.3$, & $2.8,1.9$, \\
$C_{h}$ & $4.8,3.2$ & $2.3,2.3$ & $3.1,8.0$ & $10.0,3.3$ & $2.1,4.1$ \\
\hline
\end{tabular}
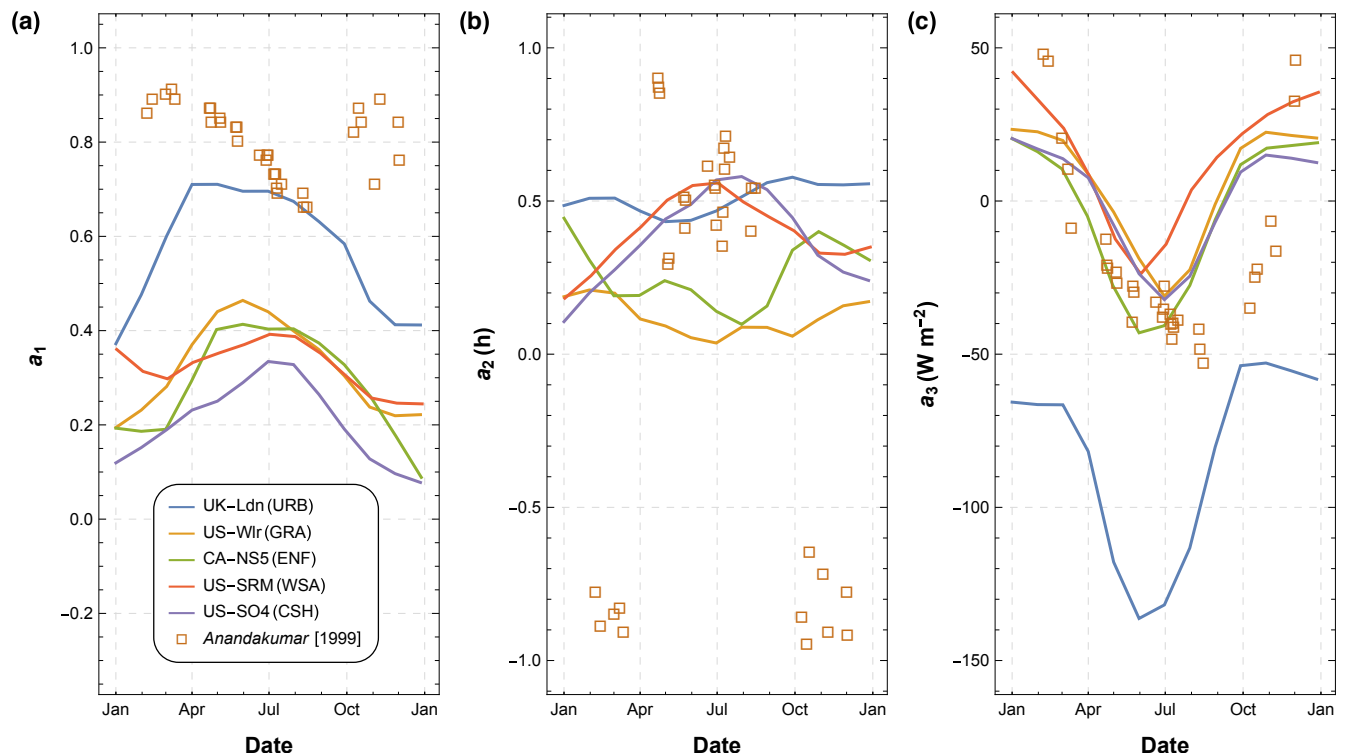

Figure 5. Intra-annual variations of OHM coefficients: (a) $a_{1}$, (b) $a_{2}$, and (c) $a_{3}$. LOESS fits (solid lines) through the daily values predicted by AnOHM and daily values (squares) measured at an asphalt road site (Anandakumar, 1999) are shown. The LOESS (Cleveland and Devlin, 2012) fitting is a locally weighted polynomial regression approach.

a more consistent $\Delta Q_{\mathrm{S}}$ with observations. Compared with OHM predictions (orange lines in Fig. 6), AnOHM (blue lines in Fig. 6) better reproduces the seasonality in $\Delta Q_{\mathrm{S}}$ but gives larger bias at two sites with natural land covers (i.e. US-SRM and US-SO4). This can be attributed to the overestimates of nocturnal $\Delta Q_{\mathrm{S}}$ by AnOHM. Overall, the evaluation demonstrates good performance of AnOHM in predicting the long-term $\Delta Q_{\mathrm{S}}$ with clear seasonality reproduced across a wide range of surface types.

\section{Discussion and concluding remarks}

In this study, the Analytical Objective Hysteresis Model (AnOHM) is developed to obtain OHM coefficients across a wide range of surface and meteorological conditions and to improve physical understanding of the interactions between $\Delta Q_{\mathrm{S}}$ and $Q^{*}$. The sensitivity of AnOHM to surface properties and hydrometeorological conditions is analysed through Monte Carlo-based subset simulations (Au and 

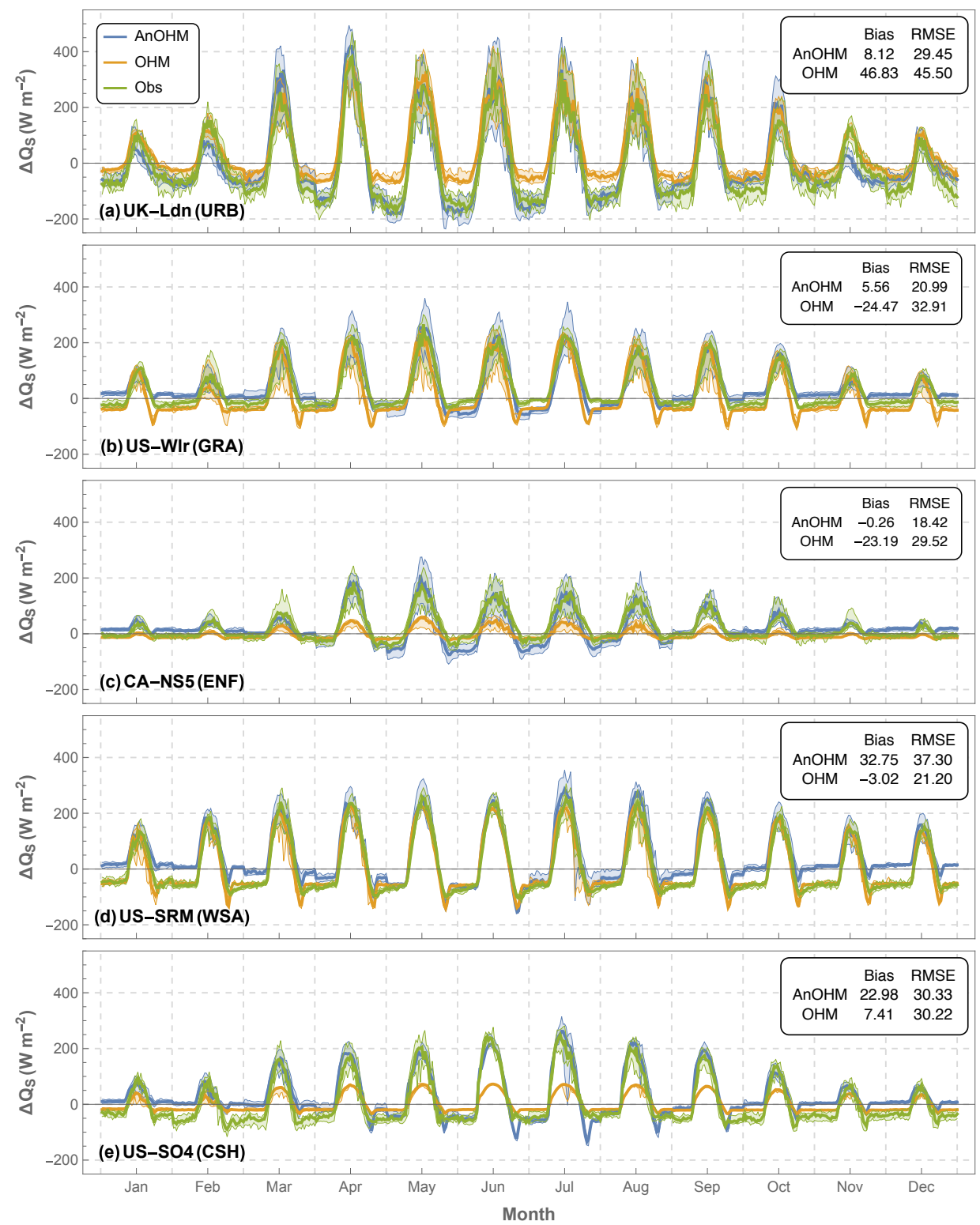

Figure 6. Monthly median (line) diurnal cycles and interquartile range (shaded) values of $\Delta Q_{\mathrm{S}}$ for AnOHM predictions (blue), OHM predictions (orange) and observations (green) at (a) UK-Ldn (URB), (b) US-Wlr (GRA), (c) CA-NS5 (ENF), (d) US-SRM (WSA), and (e) US-SO4 (CSH) (see Table 2 for site information). Statistics include average bias and RMSE ( $\mathrm{W} \mathrm{m}^{-2}$ ). The OHM coefficients $a_{1}, a_{2}$, and $a_{3}$ used for different land covers are: 0.553, 0.303, and -37.6 at the urban site (UK-Ldn) (Ward et al., 2016), 0.32, 0.54, and -27.4 at the grass-covered sites (US-Wlr and US-SRM) (Grimmond and Oke, 1999), and 0.11, 0.11, and -12.3 at the forest-covered sites (CA-NS5 and US-SO4) (Grimmond and Oke, 1999).

Beck, 2001). The results highlight the importance of the albedo, the Bowen ratio, and the bulk transfer coefficient, and the importance of solar radiation and wind speed in regulating the heat storage. The importance of albedo in modulating the heat storage was also found by Wang et al. (2011), who also used the same subset simulation approach with the single-layer urban canopy model (SLUCM; for details see Kusaka et al., 2001). This demonstrates the consistency in heat storage modelling between AnOHM and SLUCM. From the sensitivity results, variations in OHM coefficients of a similar size may arise from either surface property parameters or hydrometeorological forcing that are associated with the same physical processes (see bulk transfer coefficient $C_{h}$ in Fig. 2 and wind speed $U$ in Fig. 4). This supports the ability of AnOHM in representing physical processes. An offline evaluation of AnOHM using flux observations from five sites with different land covers demonstrates its ability to predict the intra-annual dynamics of OHM coefficients 
and shows good agreement between simulated and observed storage heat fluxes. In particular, the seasonality in the OHM coefficient $a_{3}$ observed in a previous study (Anandakumar, 1999) is well predicted by AnOHM.

The limitations of AnOHM are important to consider. First, given the assumption that the incoming solar radiation $K_{\downarrow}$ and air temperature $T_{\mathrm{a}}$ diurnal cycles are sinusoidal, optimal performance of AnOHM occurs under clear-sky conditions. The current parameterizations of $K_{\downarrow}$ and $T_{\mathrm{a}}$ within AnOHM only consider the harmonics of principal frequencies for formulation simplicity. More frequencies may potentially resolve more realistic diurnal variations in $K_{\downarrow}$ and $T_{\mathrm{a}}$. As the reflected part of $L_{\downarrow}$ (i.e. $\left(1-\varepsilon_{\mathrm{s}}\right) L_{\downarrow}$ ) is assumed negligible, and similar emissivity values are assumed for sky and land surface (i.e. $\varepsilon_{\mathrm{s}} \approx \varepsilon_{\mathrm{a}} \approx \varepsilon$ ), the outgoing longwave radiation is underestimated. These simplifications greatly facilitate the AnOHM formulation without qualitatively changing the final results as the sensitivity analyses (see the minimal $S$ values for $\varepsilon$ in Fig. 2) demonstrate. The inclusion of water flux density $W$ equips AnOHM with an ability to investigate the hydrological impacts of the underlying surface on landatmosphere interactions. However, estimation of $W$ remains challenging (Wang, 2014) and the resulting uncertainty in the final results warrants caution in conducting simulations over land covers with strong soil moisture dynamics (e.g. grassland with high soil moisture under clear-sky condition).
Despite these limitations, AnOHM does permit improved modelling of the surface energy balance through its physically based parameterization scheme for storage heat flux $\Delta Q_{\mathrm{S}}$. Compared to OHM, AnOHM has the benefit of allowing $\Delta Q_{\mathrm{S}}$ to be simulated for land covers for which coefficients are not available and to allow for seasonal variability to be accounted for. As AnOHM shares similar hydrometeorological forcing inputs (i.e. $K_{\downarrow}, T_{\mathrm{a}}$ and $U$ ) to other land surface models (LSMs), it can potentially be used within in LSMs to estimate $\Delta Q_{\mathrm{S}}$, or if turbulent fluxes are included to be a complete LSM. The overall improvements from adopting AnOHM in modelling land surface processes will be presented in forthcoming work in the SUEWS-AnOHM framework.

Code availability. The Fortran source code for AnOHM can be obtained from the corresponding authors upon request. 
Appendix A: Rationale for a simplified formulation of outgoing longwave radiation

In the formulation of outgoing longwave radiation $L_{\uparrow}$, a simplified form (i.e. $\varepsilon_{\mathrm{s}} \sigma T_{\mathrm{s}}^{4}$ ) is used for AnOHM by ignoring part 2 of Eq. (10) (i.e. $\left(1-\varepsilon_{\mathrm{s}}\right) L_{\downarrow}$ ). The rationale for such simplification is that given $\varepsilon_{\mathrm{S}}$ is usually larger than $0.9,\left(1-\varepsilon_{\mathrm{s}}\right) L_{\downarrow}$ contributes a relatively small portion to the total longwave component (Oke, 1987) and omission of this part is well accepted in the parameterization of outgoing longwave radiation for land surface modelling across various land covers (Bateni and Entekhabi, 2012; Lee et al., 2011; Stensrud, 2007).

Using the parameterization of incoming longwave radiation in the AnOHM framework (i.e. $L_{\downarrow}=\varepsilon_{\mathrm{a}} \sigma T_{\mathrm{a}}^{4} \approx \varepsilon_{\mathrm{s}} \sigma T_{\mathrm{a}}^{4}$ ), we conduct a sensitivity analysis of the ratio between the ignored part (i.e. $\left.\left(1-\varepsilon_{\mathrm{s}}\right) L_{\downarrow}\right)$ and total outgoing longwave radiation (i.e. $\left.\varepsilon_{\mathrm{S}} \sigma T_{\mathrm{S}}^{4}+\left(1-\varepsilon_{\mathrm{S}}\right) L_{\downarrow}\right)$ at a constant air temperature of $20^{\circ} \mathrm{C}$ and find this ratio is generally less than $5 \%$ given $\varepsilon_{\mathrm{S}}$ ranges between 0.90 and 0.99 (Fig. A1).

Moreover, if $\left(1-\varepsilon_{\mathrm{s}}\right) L_{\downarrow}$ is included in the net longwave radiation, the induced effect can be incorporated into a modified sky emissivity $\varepsilon_{\mathrm{a}}^{\prime}=\varepsilon_{\mathrm{s}} \varepsilon_{\mathrm{a}}$ as follows:

$$
\begin{aligned}
L_{\text {net }} & =L_{\downarrow}-L_{\uparrow} \\
& =L_{\downarrow}-\left(\varepsilon_{\mathrm{s}} \sigma T_{\mathrm{s}}^{4}+\left(1-\varepsilon_{\mathrm{s}}\right) L_{\downarrow}\right) \\
& =\varepsilon_{\mathrm{s}} L_{\downarrow}-\varepsilon_{\mathrm{s}} \sigma T_{\mathrm{s}}^{4} \\
& =\varepsilon_{\mathrm{s}} \varepsilon_{\mathrm{a}} \sigma T_{\mathrm{a}}^{4}-\varepsilon_{\mathrm{s}} \sigma T_{\mathrm{s}}^{4} \\
& =\varepsilon_{\mathrm{a}}^{\prime} \sigma T_{\mathrm{a}}^{4}-\varepsilon_{\mathrm{s}} \sigma T_{\mathrm{s}}^{4}
\end{aligned} .
$$

Then by assuming $\varepsilon \approx \varepsilon_{\mathrm{a}}^{\prime} \approx \varepsilon_{\mathrm{s}}$, the derivation following Eq. (18) still holds. The sensitivity analysis suggests that the derived coefficients are insensitive to $\varepsilon$ (see $S$ for $\varepsilon$ in Fig. 2).

As such, we deem the omission of $\left(1-\varepsilon_{\mathrm{S}}\right) L_{\downarrow}$ will not qualitatively change the results of this work.

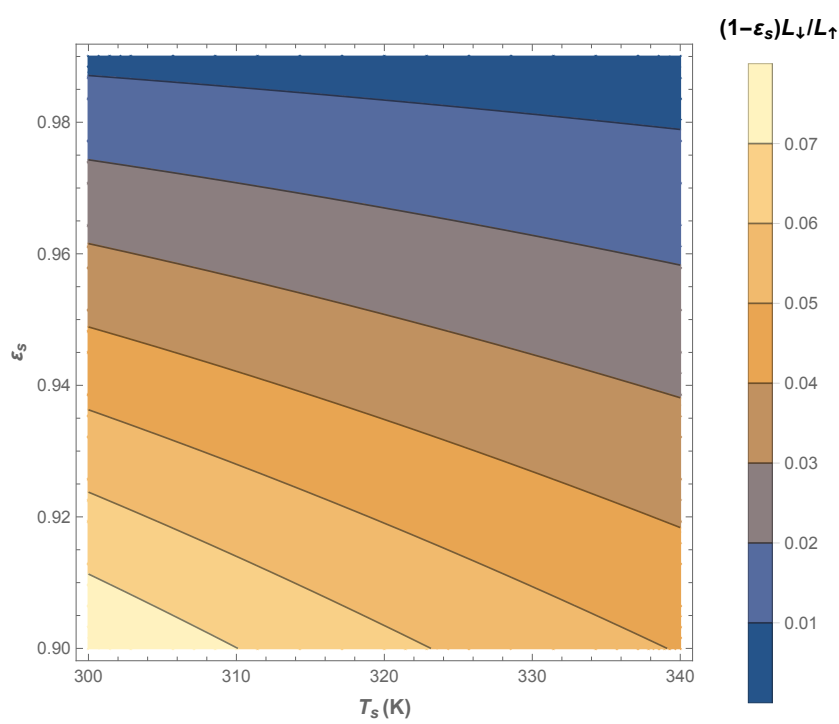

Figure A1. Ratio between the second part of Eq. (10) (i.e. $\left.\left(1-\varepsilon_{\mathrm{S}}\right) L_{\downarrow}\right)$ and total outgoing longwave radiation (i.e. $\varepsilon_{\mathrm{S}} \sigma T_{\mathrm{S}}^{4}+$ $\left.\left(1-\varepsilon_{\mathrm{S}}\right) L_{\downarrow}\right)$ at a constant air temperature of $20^{\circ} \mathrm{C}$. 
Appendix B: Comparison in OHM coefficients between different modelling approaches and observation regression

The comparison in OHM coefficients by different modelling and observational regression approaches (Fig. B1) indicate AnOHM generally follows the results by observation regression, whereas the typical coefficient values adopted by OHM do not.
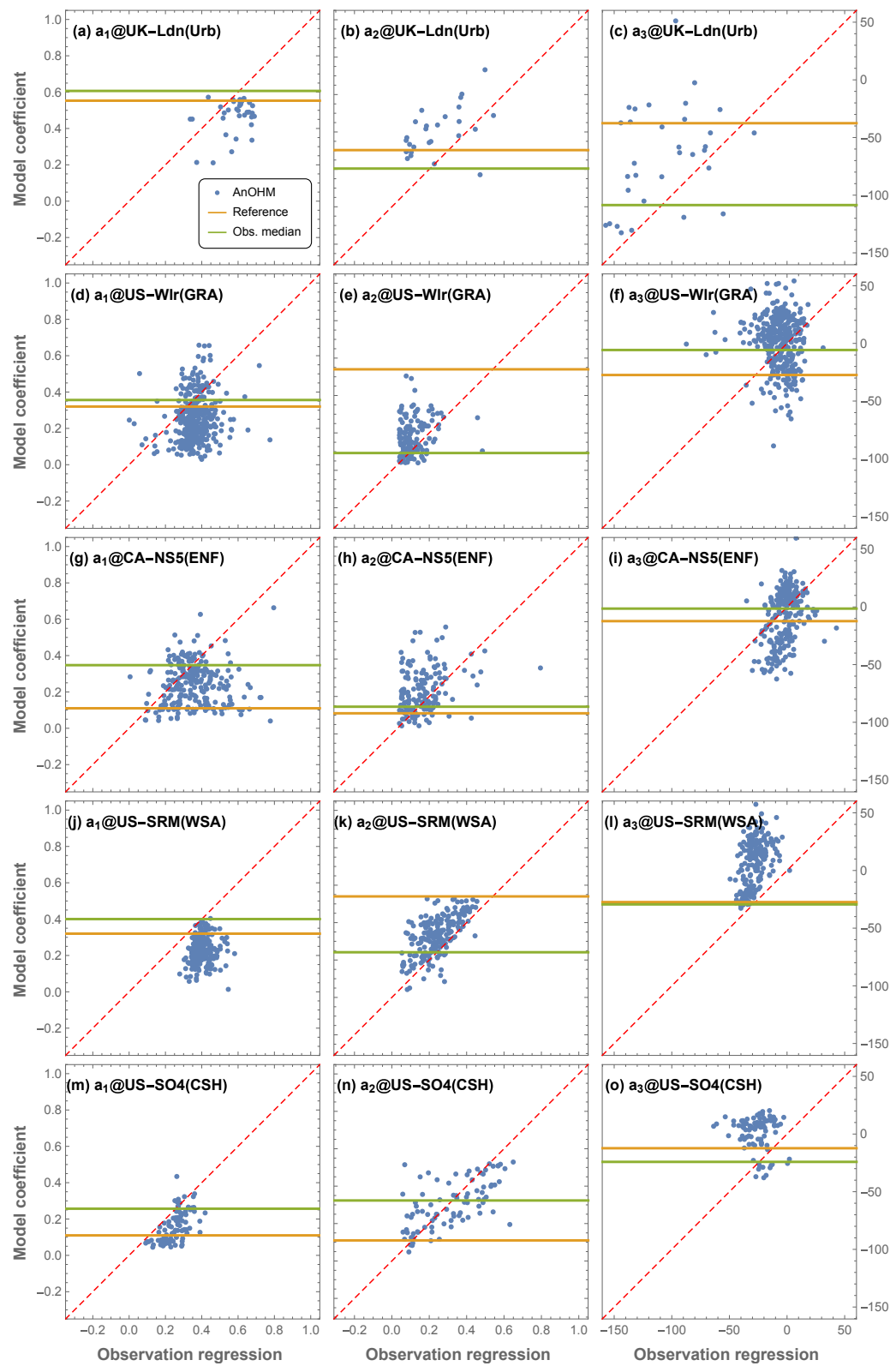

Figure B1. Comparison of OHM coefficients (left, central and right columns for $a_{1}, a_{2}$ and $a_{3}$, respectively) between different modelling approaches and observation regression at five sites: UK-Ldn (a, b, c), US-Wlr (d, e, f), CA-NS5 (g, h, i), US-SRM (j, k, l) and US-SO4 (m, n, o). The blue dots denote the paired values between AnOHM and observation regression. The orange lines represent the reference value used in OHM simulations for land covers of grass and tree (Grimmond and Oke, 1999), whereas the green lines show median values derived from results by observation regression at corresponding sites. 
Competing interests. The authors declare that they have no conflict of interest.

Acknowledgements. Funding is acknowledged from Met Office/Newton Fund CSSP- China (SG), National Science Foundation of China (51679119, TS), and U.S. National Science Foundation (CBET-1435881, ZHW). The authors thank Ivan Au (University of Liverpool) for providing the Subset Simulation package. The authors acknowledge the large number of people who have contributed to the data collection, the agencies that have provided sites and the agencies that funded the research at the individual sites. The US Department of Energy's Office of Science funded AmeriFlux data (ameriflux-data.lbl.gov) are from US-Wlr (PIs: David Cook and Richard L. Coulter), CA-NS5 (PI: Mike Goulden), US-SRM (PI: Russell Scott) and US-SO4 (PI: Walt Oechel, funded by San Diego State University and SDSU Field Stations Program). The London data are supported by NERC ClearfLo (NE/H003231/1), NERC/Belmont TRUC (NE/L008971/1), EUf7 BRIDGE (211345), H2020 UrbanFluxes (637519), King's College London and University of Reading. In particular, the authors thank Simone Kotthaus (University of Reading) for her detailed preparation of the UK-Ldn site data. For access to the UK-Ldn site data, please contact c.s.grimmond@ reading.ac.uk.

Edited by: Chiel van Heerwaarden

Reviewed by: three anonymous referees

\section{References}

Allen, L., Lindberg, F., and Grimmond, C. S. B.: Global to city scale urban anthropogenic heat flux: model and variability, Int. J. Climatol., 31, 1990-2005, https://doi.org/10.1002/joc.2210, 2011.

Anandakumar, K.: A study on the partition of net radiation into heat fluxes on a dry asphalt surface, Atmos. Environ., 33, 3911-3918, https://doi.org/10.1016/S1352-2310(99)00133-8, 1999.

Ao, X., Grimmond, C. S. B., Chang, Y., Liu, D., Tang, Y., Hu, P., Wang, Y., Zou, J., and Tan, J.: Heat, water and carbon exchanges in the tall megacity of Shanghai: challenges and results, Int. J. Climatol., 36, 4608-4624, https://doi.org/10.1002/joc.4657, 2016.

Arnfield, A. J. and Grimmond, C. S. B.: An urban canyon energy budget model and its application to urban storage heat flux modeling, Energ. Buildings, 27, 61-68, https://doi.org/10.1016/S0378-7788(97)00026-1, 1998.

$\mathrm{Au}, \mathrm{S}$. K. and Beck, J. L.: Estimation of small failure probabilities in high dimensions by subset simulation, Probabilist. Eng. Mech., 16, 263-277, https://doi.org/10.1016/S0266-8920(01)00019-4, 2001.

$\mathrm{Au}, \mathrm{S}$. K. and Beck, J. L.: Subset simulation and its application to seismic risk based on dynamic analysis, J. Eng. Mech.ASCE, 129, 901-917, https://doi.org/10.1061/(ASCE)07339399(2003)129:8(901), 2003.

$\mathrm{Au}, \mathrm{S}$. K., Ching, J., and Beck, J. L.: Application of subset simulation methods to reliability benchmark problems, Struct. Saf., 29, 183-193, https://doi.org/10.1016/j.strusafe.2006.07.008, 2007.
Bateni, S. M. and Entekhabi, D.: Relative efficiency of land surface energy balance components, Water Resour. Res., 48, W04510, https://doi.org/10.1029/2011WR011357, 2012.

Best, M. J. and Grimmond, C. S. B.: Key Conclusions of the First International Urban Land Surface Model Comparison Project, B. Am. Meteorol. Soc., 96, 805-819, https://doi.org/10.1175/BAMS-D-14-00122.1, 2015.

Best, M. J. and Grimmond, C. S. B.: Investigation of the impact of anthropogenic heat flux within an urban land surface model and PILPS-urban, Theor. Appl. Climatol., 126, 51-60, https://doi.org/10.1007/s00704-015-1554-3, 2016.

Camuffo, D. and Bernardi, A.: An observational study of heat fluxes and their relationships with net radiation, Bound.-Lay. Meteorol., 23, 359-368, https://doi.org/10.1007/BF00121121, 1982.

Chen, F. and Dudhia, J.: Coupling an advanced land surfacehydrology model with the Penn State-NCAR MM5 modeling system. Part I: Model implementation and sensitivity, Mon. Weather Rev., 129, 569-585, https://doi.org/10.1175/15200493(2001)129<0569:CAALSH>2.0.CO;2, 2001.

Ching, J. K. S., Clarke, J. F., and Godowitch, J. M.: Modulation of heat flux by different scales of advection in an urban environment, Bound.-Lay. Meteorol., 25, 171-191, https://doi.org/10.1007/BF00123973, 1983.

Chow, W. T. L., Salamanca, F. P., Georgescu, M., Mahalov, A., Milne, J. M., and Ruddell, B. L.: A multimethod and multi-scale approach for estimating city-wide anthropogenic heat fluxes, Atmos. Environ., 99, 64-76, https://doi.org/10.1016/j.atmosenv.2014.09.053, 2014.

Cleveland, W. S. and Devlin, S. J.: Locally Weighted Regression: An Approach to Regression Analysis by Local Fitting, J. Am. Stat. Assoc., 83, 596-610, https://doi.org/10.1080/01621459.1988.10478639, 1988.

Coulter, R. L., Pekour, M. S., Cook, D. R., Klazura, G. E., Martin, T. J., and Lucas, J. D.: Surface energy and carbon dioxide fluxes above different vegetation types within ABLE, Agr. Forest. Meteorol., 136, 147-158, https://doi.org/10.1016/j.agrformet.2004.11.011, 2006.

Doll, D., Ching, J., and Kaneshiro, J.: Parameterization of subsurface heating for soil and concrete using net radiation data, Bound.-Lay. Meteorol., 32, 351-372, https://doi.org/10.1007/BF00122000, 1985.

Gao, Z., Fan, X. G., and Bian, L. G.: An analytical solution to one-dimensional thermal conductionconvection in soil, Soil Sci., 168, 99-107, https://doi.org/10.1097/01.ss.0000055305.23789.be, 2003.

Gao, Z., Lenschow, D. H., Horton, R., Zhou, M., Wang, L., and Wen, J.: Comparison of two soil temperature algorithms for a bare ground site on the Loess Plateau in China, J. Geophys. Res.Oceans, 113, D18105, https://doi.org/10.1029/2008JD010285, 2008.

Gao, Z., Horton, R., and Liu, H. P.: Impact of wave phase difference between soil surface heat flux and soil surface temperature on soil surface energy balance closure, J. Geophys. Res., 115, D16112, https://doi.org/10.1029/2009JD013278, 2010.

Goulden, M. L., Winston, G. C., McMillan, A. M. S., Litvak, M. E., Read, E. L., Rocha, A. V., and Elliot, J. R.: An eddy covariance mesonet to measure the effect of forest age on land-atmosphere exchange, Glob. Change Biol., 12, 2146-2162, https://doi.org/10.1111/j.1365-2486.2006.01251.x, 2006. 
Grimmond, C. S. B. and Oke, T. R.: Heat storage in urban areas: local-scale observations and evaluation of a simple model, J. Appl. Meteorol., 38, 922-940, https://doi.org/10.1175/15200450(1999)038<0922:HSIUAL>2.0.CO;2, 1999.

Grimmond, C. S. B. and Oke, T. R.: Turbulent heat fluxes in urban areas: Observations and a local-scale urban meteorological parameterization scheme (LUMPS), J. Appl. Meteorol., 41, 792-810, https://doi.org/10.1175/15200450(2002)041<0792:thfiua>2.0.co;2, 2002.

Grimmond, C. S. B., Cleugh, H. A., and Oke, T. R.: An objective urban heat storage model and its comparison with other schemes, Atmos. Environ. B, 25, 311-326, https://doi.org/10.1016/09571272(91)90003-W, 1991.

Grimmond, C. S. B., Blackett, M., Best, M. J., Baik, J. J., Belcher, S. E., Beringer, J., Bohnenstengel, S. I., Calmet, I., Chen, F., Coutts, A., Dandou, A., Fortuniak, K., Gouvea, M. L., Hamdi, R., Hendry, M., Kanda, M., Kawai, T., Kawamoto, Y., Kondo, H., Krayenhoff, E. S., Lee, S.-H., Loridan, T., Martilli, A., Masson, V., Miao, S., Oleson, K., Ooka, R., Pigeon, G., Porson, A., Ryu, Y.-H., Salamanca, F. P., Steeneveld, G. J., Tombrou, M., Voogt, J. A., Young, D. T., and Zhang, N.: Initial results from Phase 2 of the international urban energy balance model comparison, Int. J. Climatol., 31, 244-272, https://doi.org/10.1002/joc.2227, 2011.

Hastings, W. K.: Monte carlo sampling methods using Markov chains and their applications, Biometrika, 57, 97-109, https://doi.org/10.1093/biomet/57.1.97, 1970.

Iamarino, M., Beevers, S., and Grimmond, C. S. B.: Highresolution (space, time) anthropogenic heat emissions: London 1970-2025, Int. J. Climatol., 32, 1754-1767, https://doi.org/10.1002/joc.2390, 2011.

Järvi, L., Grimmond, C. S. B., and Christen, A.: The Surface Urban Energy and Water Balance Scheme (SUEWS): Evaluation in Los Angeles and Vancouver, J. Hydrol., 411, 219-237, https://doi.org/10.1016/j.jhydrol.2011.10.001, 2011.

Järvi, L., Grimmond, C. S. B., Taka, M., Nordbo, A., Setälä, H., and Strachan, I. B.: Development of the Surface Urban Energy and Water Balance Scheme (SUEWS) for cold climate cities, Geosci. Model Dev., 7, 1691-1711, https://doi.org/10.5194/gmd-7-16912014, 2014.

Karsisto, P., Fortelius, C., Demuzere, M., Grimmond, C. S. B., Oleson, K. W., Kouznetsov, R., Masson, V., and Järvi, L.: Seasonal surface urban energy balance and wintertime stability simulated using three land-surface models in the highlatitude city Helsinki, Q. J. Roy. Meteor. Soc., 142, 401-417, https://doi.org/10.1002/qj.2659, 2015.

Katul, G. G., Oren, R., Manzoni, S., Higgins, C. W., and Parlange, M. B.: Evapotranspiration: a process driving mass transport and energy exchange in the soil-plantatmosphere-climate system, Rev. Geophys., 50, RG3002, https://doi.org/10.1029/2011RG000366, 2012.

Kerschgens, M. J. and Drauschke, R. L.: On the energy budget of a wintry mid-latitude city atmosphere, Beiträge zur Physik der Atmosphäre, 59, 115-125, 1986.

Kerschgens, M. J. and Hacker, J. M.: On the energy budget of the convective boundary layer over an urban and rural environment, Beiträge zur Physik der Atmosphäre, 58, 171-185, 1985.

Kerschgens, M. J. and Kraus, H.: On the energetics of the urban canopy layer, Atmos. Environ., 24, 321-328, https://doi.org/10.1016/0957-1272(90)90038-V, 1990.
Klazura, G. E., Cook, D. R., Coulter, R. L., Hart, R. L., Holdridge, D. J., Lesht, B. M., Lucas, J. D., Martin, T. J., Pekour, M. S., and Wesely, M. L.: Atmospheric boundary layer measurements in south-central Kansas, 1997-2004, B. Am. Meteorol. Soc., 87, 1319-1324, https://doi.org/10.1175/BAMS-87-10-1319, 2006.

Kotthaus, S. and Grimmond, C. S. B.: Energy exchange in a dense urban environment - Part I: Temporal variability of long-term observations in central London, Urban Climate, 10, 261-280, https://doi.org/10.1016/j.uclim.2013.10.002, 2014a.

Kotthaus, S. and Grimmond, C. S. B.: Energy exchange in a dense urban environment - Part II: Impact of spatial heterogeneity of the surface, Urban Climate, 10, 281-307, https://doi.org/10.1016/j.uclim.2013.10.001, 2014b.

Kotthaus, S., Smith, T. E. L., Wooster, M. J. and Grimmond, C. S. B.: Derivation of an urban materials spectral library through emittance and reflectance spectroscopy, ISPRS J. Photogramm., 94, 194-212, https://doi.org/10.1016/j.isprsjprs.2014.05.005, 2014.

Kusaka, H., Kondo, H., Kikegawa, Y., and Kimura, F.: A Simple Single-Layer Urban Canopy Model For Atmospheric Models: Comparison With Multi-Layer And Slab Models, Bound.-Lay. Meteorol., 101, 329-358-358, https://doi.org/10.1023/A:1019207923078, 2001.

Lee, X., Goulden, M. L., Hollinger, D. Y., Barr, A., Black, T. A., Bohrer, G., Bracho, R., Drake, B., Goldstein, A., Gu, L., Katul, G. G., Kolb, T., Law, B. E., Margolis, H., Meyers, T., Monson, R., Munger, W., Oren, R., U, K. T. P., Richardson, A. D., Schmid, H. P., Staebler, R., Wofsy, S., and Zhao, L.: Observed increase in local cooling effect of deforestation at higher latitudes, Nature, 479, 384-387, https://doi.org/10.1038/nature10588, 2011.

Li, D., Sun, T., Liu, M., Yang, L., Wang, L., and Gao, Z.: Contrasting responses of urban and rural surface energy budgets to heat waves explain synergies between urban heat islands and heat waves, Environ. Res. Lett., 10, 054009, https://doi.org/10.1088/1748-9326/10/5/054009, 2015.

Liang, X., Lettenmaier, D. P., Wood, E. F., and Burges, S. J.: A simple hydrologically based model of land surface water and energy fluxes for general circulation models, J. Geophys. Res., 99, 14415-14428, https://doi.org/10.1029/94JD00483, 1994.

Lipson, M. J., Hart, M. A., and Thatcher, M.: Efficiently modelling urban heat storage: an interface conduction scheme in an urban land surface model (aTEB v2.0), Geosci. Model Dev., 10, 9911007, https://doi.org/10.5194/gmd-10-991-2017, 2017.

Luo, H., Oechel, W. C., Hastings, S. J., Zulueta, R., Qian, Y., and Kwon, H.: Mature semiarid chaparral ecosystems can be a significant sink for atmospheric carbon dioxide, Glob. Change Biol., 13, 386-396, https://doi.org/10.1111/j.1365-2486.2006.01299.x, 2007.

Masson, V., Grimmond, C. S. B., and Oke, T. R.: Evaluation of the Town Energy Balance (TEB) scheme with direct measurements from dry districts in two cities, J. Appl. Meteorol., 41, 1011-1026, https://doi.org/10.1175/15200450(2002)041<1011:EOTTEB>2.0.CO;2, 2002.

McCumber, M. C. and Pielke, R. A.: Simulation of the effects of surface fluxes of heat and moisture in a mesoscale numerical model: 1. Soil layer, J. Geophys. Res.-Oceans, 86, 9929-9938, https://doi.org/10.1029/JC086iC10p09929, 1981.

Metropolis, N., Rosenbluth, A. W., Rosenbluth, M. N., Teller, A. H., and Teller, E.: Equation of State Calculations by 
Fast Computing Machines, J. Chem. Phys., 21, 1087-1092, https://doi.org/10.1063/1.1699114, 1953.

Meyn, S. K. and Oke, T. R.: Heat fluxes through roofs and their relevance to estimates of urban heat storage, Energ. Buildings, 41, 745-752, https://doi.org/10.1016/j.enbuild.2009.02.005, 2009.

Nie, W.-S., Sun, T., and Ni, G.-H.: Spatiotemporal characteristics of anthropogenic heat in an urban environment: A case study of Tsinghua Campus, Build. Environ., 82, 675-686, https://doi.org/10.1016/j.buildenv.2014.10.011, 2014.

Offerle, B. D., Grimmond, C. S. B., and Fortuniak, K.: Heat storage and anthropogenic heat flux in relation to the energy balance of a central European city centre, Int. J. Climatol., 25, 1405-1419, https://doi.org/10.1002/joc.1198, 2005.

Oke, T. R.: Boundary Layer Climates, Taylor \& Francis, Abingdon, Ukm 1987.

Oke, T. R.: The urban energy balance, Prog. Phys. Geog., 12, 471508, https://doi.org/10.1177/030913338801200401, 1988.

Oke, T. R. and Cleugh, H. A.: Urban heat storage derived as energy balance residuals, Bound.-Lay. Meteorol., 39, 233-245, https://doi.org/10.1007/BF00116120, 1987.

Oke, T. R., Kalanda, B. D., and Steyn, D. G.: Parameterization of heat storage in urban areas, Urban Ecol., 5, 45-54, https://doi.org/10.1016/0304-4009(81)90020-6, 1981.

Oliphant, A. J., Grimmond, C. S. B., Zutter, H. N., Schmid, H. P., Su, H. B., Scott, S. L., Offerle, B. D., Randolph, J. C., and Ehman, J.: Heat storage and energy balance fluxes for a temperate deciduous forest, Agr. Forest. Meteorol., 126, 185-201, https://doi.org/10.1016/j.agrformet.2004.07.003, 2004.

Pauwels, V. R. N. and Daly, E.: Advantages of analytically computing the ground heat flux in land surface models, Hydrol. Earth Syst. Sci., 20, 4689-4706, https://doi.org/10.5194/hess-20-46892016, 2016.

Ren, T., Kluitenberg, G. J., and Horton, R.: Determining Soil Water Flux and Pore Water Velocity by a Heat Pulse Technique, Soil Sci. Soc. Am. J., 64, 552, https://doi.org/10.2136/sssaj2000.642552x, 2000.

Roberts, S. M., Oke, T. R., Grimmond, C. S. B., and Voogt, J. A.: Comparison of Four Methods to Estimate Urban Heat Storage, J. Appl. Meteorol., 45, 1766-1781, https://doi.org/10.1175/jam2432.1, 2006.

Roth, M. and Oke, T. R.: Relative Efficiencies of Turbulent Transfer of Heat, Mass, and Momentum over a Patchy Urban Surface, J. Atmos. Sci., 52, 1863-1874, https://doi.org/10.1175/15200469(1995)052<1863:reotto>2.0.co;2, 1995.

Sailor, D. J.: A review of methods for estimating anthropogenic heat and moisture emissions in the urban environment, edited by: Roth, M., Emmanuel, R., Ichinose, T., and Salmond, J., Int. J. Climatol., 31, 189-199, https://doi.org/10.1002/joc.2106, 2011.

Scott, R. L., Jenerette, G. D., Potts, D. L., and Huxman, T. E.: Effects of seasonal drought on net carbon dioxide exchange from a woody-plant-encroached semiarid grassland, J. Geophys. Res.Biogeo., 114, G04004, https://doi.org/10.1029/2008JG000900, 2009.

Sellers, P. J., Dickinson, R. E., Randall, D. A., Betts, A. K., Hall, F. G., Berry, J. A., Collatz, G. J., Denning, A. S., Mooney, H. A., Nobre, C. A., Sato, N., Field, C. B., and Henderson-Sellers, A.: Modeling the Exchanges of Energy, Water, and Carbon Between Continents and the Atmosphere, Science, 275, 502-509, https://doi.org/10.1126/science.275.5299.502, 1997.
Souch, C., Grimmond, C. S. B., and Wolfe, C. P.: Evapotranspiration rates from wetlands with different disturbance histories: Indiana Dunes National Lakeshore, Wetlands, 18, 216-229, https://doi.org/10.1007/BF03161657, 1998.

Staley, D. O. and Jurica, G. M.: Effective Atmospheric Emissivity under Clear Skies, J. Appl. Meteorol., 11, 349-356, https://doi.org/10.1175/15200450(1972)011<0349:eaeucs>2.0.co;2, 1972.

Stensrud, D. J.: Parameterization schemes: keys to understanding numerical weather prediction models, Cambridge University Press, Cambridge, 2007.

Stull, R.: An Introduction to boundary layer meteorology, Springer, 1988.

Sun, T., Wang, Z.-H., and Ni, G.-H.: Revisiting the hysteresis effect in surface energy budgets, Geophys. Res. Lett., 40, 1741-1747, https://doi.org/10.1002/grl.50385, 2013.

Wang, Z.-H.: Reconstruction of soil thermal field from a single depth measurement, J. Hydrol., 464-465, 541-549, https://doi.org/10.1016/j.jhydrol.2012.07.047, 2012.

Wang, Z.-H.: A new perspective of urban-rural differences: The impact of soil water advection, Urban Climate, 10, 19-34, https://doi.org/10.1016/j.uclim.2014.08.004, 2014.

Wang, Z.-H., Bou-Zeid, E., and Smith, J. A.: A coupled energy transport and hydrological model for urban canopies evaluated using a wireless sensor network, Q. J. Roy. Meteor. Soc., 139, 1643-1657, https://doi.org/10.1002/qj.2032, 2012.

Wang, Z.-H., Bou-Zeid, E., Au, S. K., and Smith, J. A.: Analyzing the Sensitivity of WRF's Single-Layer Urban Canopy Model to Parameter Uncertainty Using Advanced Monte Carlo Simulation, J. Appl. Meteorol. Clim., 50, 1795-1814, https://doi.org/10.1175/2011JAMC2685.1, 2011.

Ward, H. C., Evans, J. G., and Grimmond, C. S. B.: Multi-season eddy covariance observations of energy, water and carbon fluxes over a suburban area in Swindon, UK, Atmos. Chem. Phys., 13, 4645-4666, https://doi.org/10.5194/acp-13-4645-2013, 2013.

Ward, H. C., Kotthaus, S., Järvi, L., and Grimmond, C. S. B.: Surface Urban Energy and Water Balance Scheme (SUEWS): Development and evaluation at two UK sites, Urban Climate, 18, 1-32, https://doi.org/10.1016/j.uclim.2016.05.001, 2016.

Yang, J. and Wang, Z.-H.: Land surface energy partitioning revisited: A novel approach based on single depth soil measurement, Geophys. Res. Lett., 41, 8348-8358, https://doi.org/10.1002/2014GL062041, 2014.

Yang, J., Wang, Z.-H., Chen, F., Miao, S., Tewari, M., Voogt, J. A., and Myint, S.: Enhancing Hydrologic Modelling in the Coupled Weather Research and ForecastingUrban Modelling System, Bound.-Lay. Meteorol., 155, 1-23, https://doi.org/10.1007/s10546-014-9991-6, 2014. 